\title{
Physical, Mechanical and Durability Properties of Soil Building Blocks Reinforced with Natural Fibres
}

\author{
Humphrey Danso ${ }^{\text {a,b, }, \text { D. Brett Martinson }}{ }^{\text {a }}$, Muhammad Ali a , John B. Williams ${ }^{\text {a }}$ \\ ${ }^{a}$ School of Civil Engineering and Surveying, University of Portsmouth, Portland Building, Portland Street, \\ Portsmouth PO1 3AH, United Kingdom \\ ${ }^{\mathrm{b}}$ Department of Construction \& Wood Technology Education, University of Education Winneba, P. O. Box \\ 1277, Kumasi, Ghana \\ * Tel.: +44 (0)7459636959, +44 (0)2392842428; fax: +44 (0)2392842521. \\ E-mail address: Humphrey.danso@port.ac.uk (H. Danso).
}

\begin{abstract}
This study investigates the properties of soil blocks stabilised with fibres from agricultural waste. Laboratory experiments including density, water absorption, shrinkage, compressive strength, tensile strength, wearing and erosion were conducted on soil blocks made with two soil types and enhanced with three fibre types at $0.25-1 \mathrm{wt} . \% \mathrm{t}$. It was found that the physical, mechanical and durability properties of the blocks were generally improved and a recommendation of $0.5 \mathrm{wt} . \%$ fibre content and high clayey soil are made. Many assumptions about relationships between properties established for binder stabilised blocks are found to be inappropriate for fibre reinforced blocks.
\end{abstract}

Keywords: agricultural waste fibres, natural fibres, soil blocks, density, water absorption, linear shrinkage, compressive strength, tensile strength, erosion test

\section{INTRODUCTION}

Conventional construction and building materials such as steel bar, cement, concrete, sandcrete blocks, burnt bricks and tiles require the extraction of large quantities of materials, causing depletion of natural resources and environmental damage. The manufacturing process of these materials is energy intensive, releasing carbon dioxide and other pollutants such as particulate matter, sulphur oxides, nitrogen oxides and carbon monoxide into the atmosphere. These emissions contaminate water, air, soil, flora, fauna and aquatic life as well as affecting human health [1]. In addition, the cost of conventional building materials keeps increasing because of the energy required for the production, increasing scarcity of natural resources and high transportation cost from the factories to the construction site. These environmental and economic concerns have generated interest in research into alternate 
building materials, such as soil building blocks, and construction techniques that are more sustainable.

Soil building blocks enhanced with agricultural waste are one of the alternate building materials that have shown to provide social, environmental and economically sustainable buildings [2]. These have been used to produce low-cost housing, improved thermal comfort and for maintaining cultural heritage buildings. The advantage of agricultural waste fibres is their availability in many economies, since most countries have significant agricultural activity [3]. Different agricultural wastes can be found in different countries depending on the type of crops available. For example, there are abundant wastes generated in Ghana from coconut husk, sugarcane residue (bagasse) and oil palm fruit residue. Different agricultural wastes have therefore been used to enhance the properties of soil blocks in different countries.

The use of wastes as alternate building material has had a great deal of interest in recent years. Industrial wastes such as blast furnace slag [4], phosphogypsum and natural gypsum [5], coal combustion by-products [6], salvaged steel fibres from used tyres [7], sawdust [8], crumb rubber [9] and plastics [10] have been used to enhance the properties of soil building blocks/bricks. Animal wastes such as sheep wool fibre [11] and cow-dung [8] have also been used to enhance the properties of soil building blocks/bricks. Furthermore, agricultural wastes such as chopped barley straw [12, 13], processed waste tea [14], seaweed [15], oil palm empty fruit bunches [16], lechuguilla [17], pineapple leaves [18], cassava peel [6], hibiscus cannabinus [19], date palm [20] and coir [21, 22] have been investigated. These studies have shown that the presence of waste fibre has often improved the properties of the soil blocks.

The aim of this study is to investigate the properties of soil building blocks reinforced with three fibres, namely sugarcane bagasse, oil palm fruit and coconut husk in two different soils. To achieve this, the physical, mechanical and durability properties of the fibre reinforced soil blocks were measured and optimum fibre content determined. The applicability of proxy measures, such as physical properties for strength and durability, were then evaluated as these have been shown to be applicable to blocks reinforced with binders, such as Portland cement $[23,24]$, but not well defined for blocks reinforced with fibres. The relative importance of soil-type and fibre type in determining the properties of fibre reinforced earth blocks were then assessed. These were then compared to the published criteria for soil suitability which have been generally developed for binder stabilised blocks [25] and therefore may not be 
appropriate for fibres. This work extends the existing database of different fibres used for reinforcement of soils blocks across a range of performance measures and evaluates them against the existing guidance.

\section{MATERIALS AND METHODS}

The practical work was undertaken in Ghana where earth/soil block construction is a common technique for low-cost housing, particularly in rural areas. To ensure the study was applicable to other countries soils were selected to cover a range of properties and fibres were selected from widely available waste products.

\subsection{Materials}

The principal materials used for the experiment are soil and agricultural waste fibres. Red (R) soil and Brown (B) soil from Ghana were selected as these are the two main soil types that are used for earthen construction in Ghana, and represent the main types of soil used for constructing soil block houses. They also represent a range of properties with one of the soils (B) within the limits generally specified for earth construction, while the other $(R)$ is partially outside the limits. The properties of the soils are reported in Table 1. The particle size distribution curve is shown in Fig 1, with the lower and upper limits usually recommended for soil blocks.

Table 1: Properties of the experimental soil

\begin{tabular}{|c|c|c|}
\hline \multirow[t]{2}{*}{ Properties } & \multicolumn{2}{|c|}{ Soil type } \\
\hline & Brown & Red \\
\hline \multicolumn{3}{|l|}{ Proctor test } \\
\hline Optimum moisture content (\%) & 18 & 19 \\
\hline Maximum dry density $\left(\mathrm{Mg} / \mathrm{m}^{3}\right)$ & 1.78 & 1.79 \\
\hline \multicolumn{3}{|l|}{ Atterberg limits } \\
\hline Liquid limit $w_{\mathrm{L}}(\%)$ & 13.3 & 51.2 \\
\hline Plastic limit $w_{\mathrm{p}}(\%)$ & 17.2 & 27.3 \\
\hline Plasticity index $I p$ & 13.9 & 23.9 \\
\hline \multicolumn{3}{|l|}{ Soil classification } \\
\hline USCS & CL & $\mathrm{CH}$ \\
\hline \multicolumn{3}{|l|}{ Particle size distribution } \\
\hline Gravel (>2 mm) (\%) & 12 & 15 \\
\hline Sand $(2-0.063 \mathrm{~mm})(\%)$ & 46 & 39 \\
\hline Silt $(0.063-0.002 \mathrm{~mm})(\%)$ & 28 & 16 \\
\hline Clay $(<0.002 \mathrm{~mm})(\%)$ & 14 & 30 \\
\hline \multicolumn{3}{|l|}{$p H$} \\
\hline Value & 7.33 & 7.44 \\
\hline \multicolumn{3}{|l|}{ Chemical composition $(\mathrm{mg} / \mathrm{kg}$ ) } \\
\hline $\mathrm{Al}^{3+}$ & 0.06 & 0.09 \\
\hline $\mathrm{Ca}^{2+}$ & 44.0 & 65.0 \\
\hline $\mathrm{SiO}_{2}$ & 0.06 & 0.08 \\
\hline $\mathrm{K}$ & 3.88 & 4.19 \\
\hline $\mathrm{Zn}$ & 0.86 & 0.91 \\
\hline
\end{tabular}




\begin{tabular}{lcc}
$\mathrm{Pb}$ & 0.10 & 0.15 \\
$\mathrm{Fe}^{2+}$ & 1.038 & 1.047 \\
$\mathrm{Mg}^{2+}$ & 14.8 & 15.80 \\
$\mathrm{Cl}^{-}$ & 18.99 & 31.49 \\
$\mathrm{PO}_{4}{ }^{3-}$ & 6.17 & 3.09 \\
$\mathrm{SO}_{4}{ }^{2-}$ & 20.0 & 28.0 \\
\hline
\end{tabular}

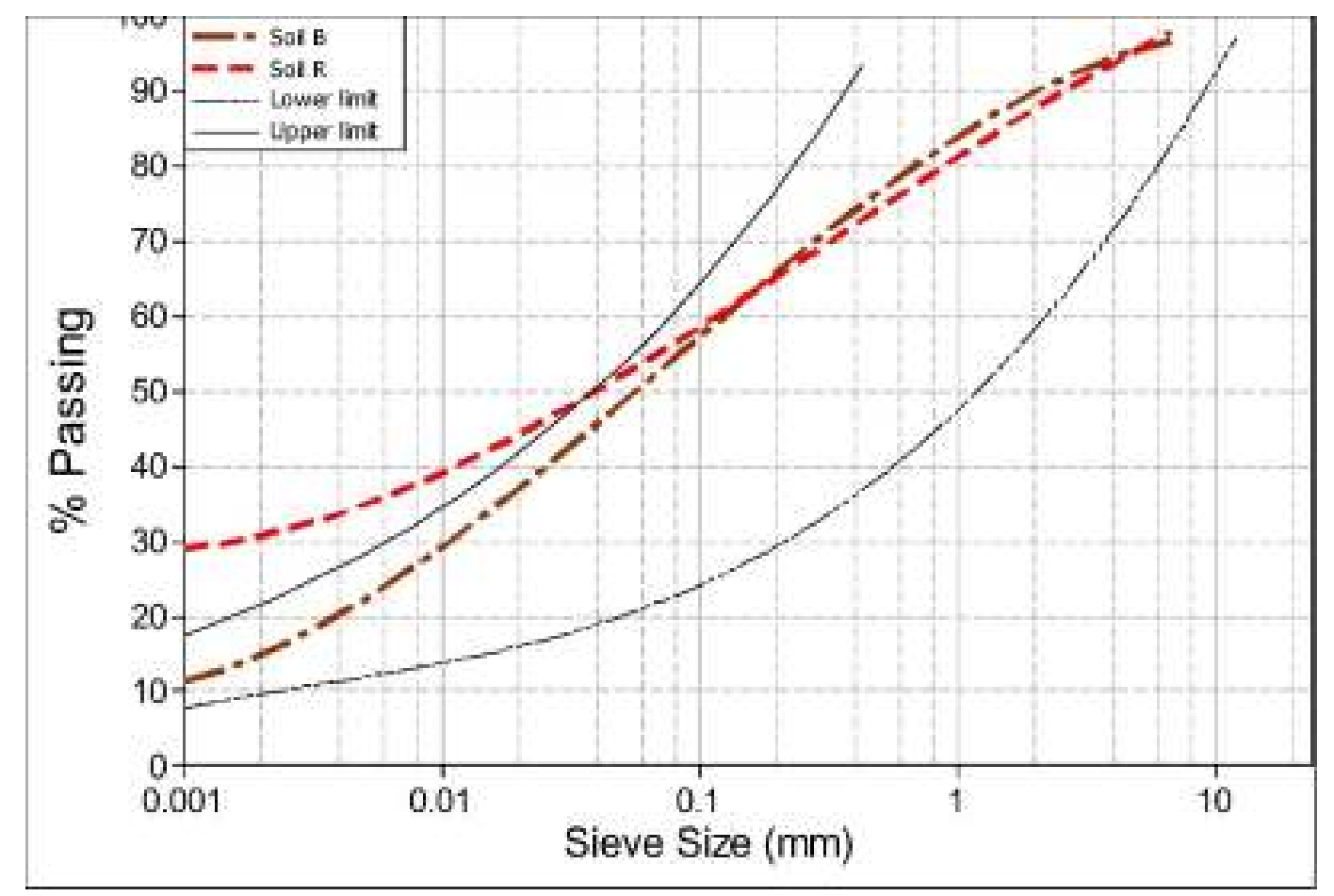

Figure 1: Particle size distribution of the experimental soil

The results indicate that soil B is low plasticity clay (CL) soil which lies within the limits, while soil $\mathrm{R}$ is high plasticity clay $(\mathrm{CH})$ soil which lies partially outside the limits according to unified soil classification system (USCS) [26]. Chemical element/composition of the soil was determined through inductively coupled plasma - mass spectrometry (ICP-MS) analysis method in accordance with BS EN ISO 17294-1 [27] and the result is also reported in Table 1.

Stabilisation was achieved by using coconut husk, bagasse and oil palm fruit fibres in the production of soil blocks. These fibres have been selected as they cover a wide range of properties, and are also abundant agricultural waste materials in West Africa. More 
information on these fibres can be found in a previous study [2]. Each fibre type is illustrated in Fig 2. SEM images of single fibre were determined with JSM-6100 scanning microscope at 35 and 500x magnification for each fibre type to show the texture of the fibres. It can be seen that the bagasse fibres are very rough in texture as compared to coconut and oil palm fibres. The oil palm fibres also appear slightly smoother than the coconut. The properties of the fibres were measured according to methods developed by Ghavami et al. [28] for determining the properties of natural fibres such as bamboo, sisal and coconut. The properties of the selected fibres are reported in Table 2, the lengths of the fibres used were a result of the optimum lengths that produced maximum strength in the previous study [2].

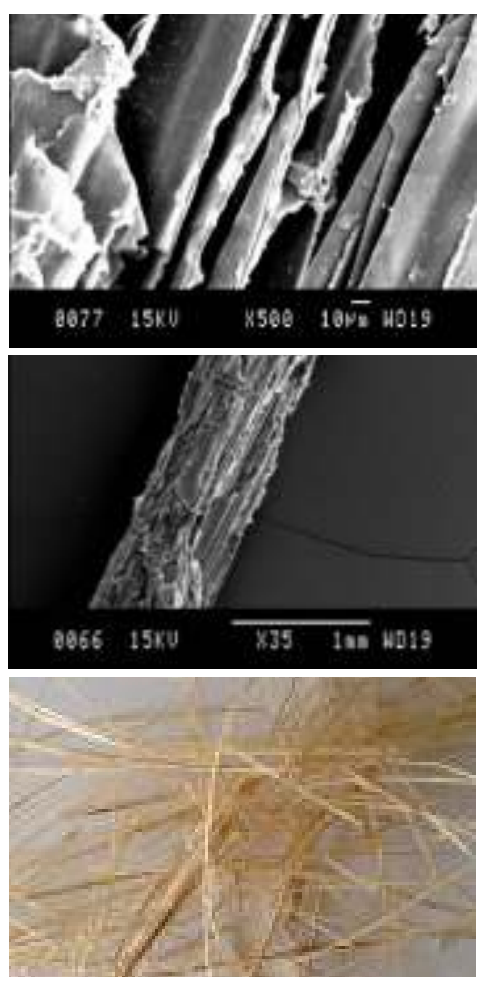

Bagasse fibre
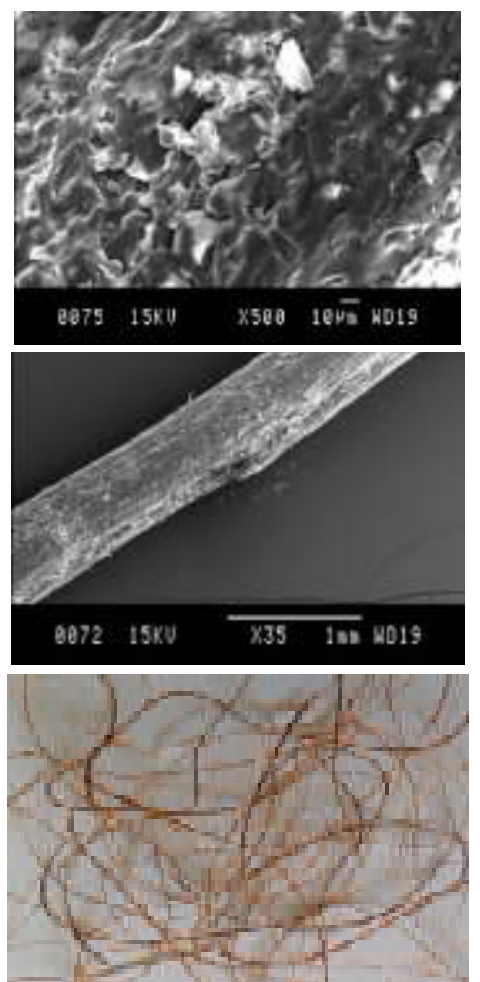

Coconut fibre
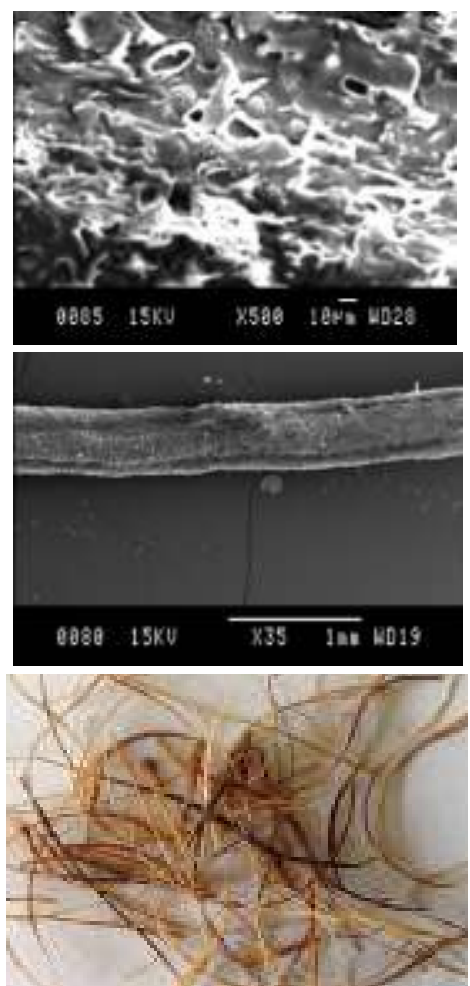

Oil palm fibre

Figure 2: Photographs and SEM micrographs of the types of fibre

Table 2: Properties of experimental fibres

\begin{tabular}{lccc}
\hline Property & \multicolumn{3}{c}{ Fibre type } \\
\cline { 2 - 4 } & Coconut & Oil Palm & Bagasse \\
\hline Fibre form & Single & Single & Single \\
Cut length $(\mathrm{mm})$ & 50 & 38 & 80 \\
Range of diameter $(\mathrm{mm})$ & $1.01-0.18$ & $0.82-0.19$ & $1.19-0.31$ \\
Tensile strength $(\mathrm{MPa})$ & $222-83$ & $141-65$ & $62-25$ \\
Modulus of elasticity $(\mathrm{GPa})$ & $2.8-2.3$ & $1.1-0.7$ & $1.3-0.5$ \\
Specific weight $\left(\mathrm{g} / \mathrm{cm}^{3}\right)$ & 0.81 & 0.77 & 0.56 \\
Natural moisture content $(\%)$ & 6.4 & 7.4 & 9.7 \\
Water absorption $(\%)$ & $209-145$ & $103-54$ & $219-153$ \\
\hline
\end{tabular}




\subsection{Methods}

The blocks were tested for density, water absorption, linear shrinkage, compressive strength, splitting tensile strength, wearing and erosion. These tests were selected to cover a wide range of properties important for soil blocks, such as physical, mechanical and durability after a review of previous studies [29]. Five blocks from each mix ratio, fibre type and soil type were randomly selected and used for each test.

\subsubsection{Preparation of blocks}

Soil blocks of $290 \times 140 \times 100 \mathrm{~mm}$ were made with soil and $0.25,0.5,0.75$ and $1 \mathrm{wt} . \%$ fibre content. The soil was first spread on a platform, then the fibre was spread on top and turned over and over until a uniform mixture was obtained. Water was added to achieve the optimum moisture content (OMC) (Table 1) by sprinkling on to the soil-fibre mixture and repeatedly turned to obtain a homogenous mixture. It must be noted that the OMC was for the soil without fibres. The fibres were soaked in water for $48 \mathrm{hr}$ to saturation before being added to the mix. The blocks were made with BREPAC block making machine with a constant pressure of $10 \mathrm{MPa}$ (Fig 3). They were sun dried (Fig 4) at an average temperature of $27^{\circ} \mathrm{C}$ and relative humidity of $72 \%$ for 21 days. The blocks were packed and the surfaces cleaned with soft duster before testing.

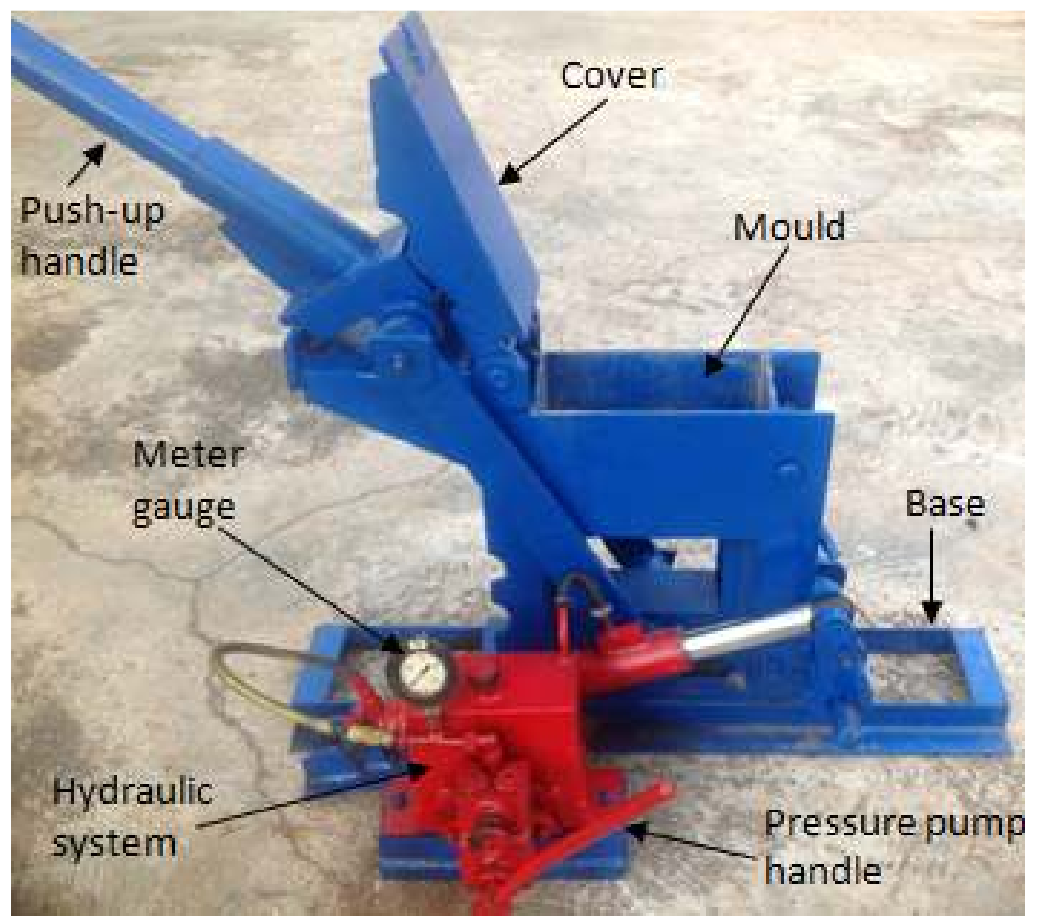

Figure 3: Pressure gauge block making machine 


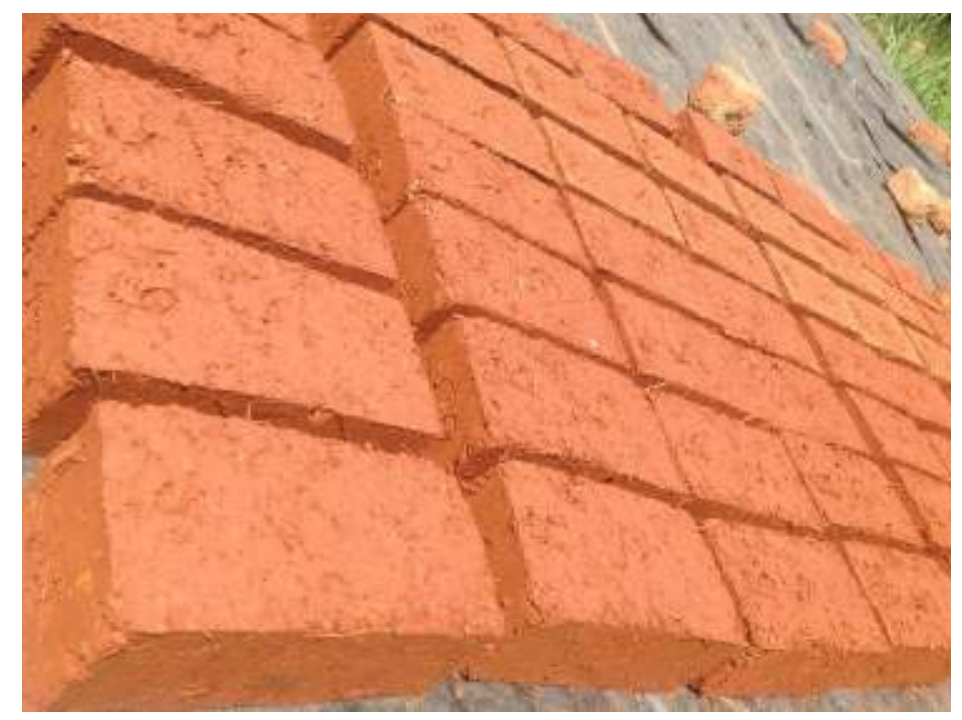

\subsubsection{Physical properties tests}

Figure 4: Drying of enhanced soil blocks

Density of the specimen was determined in accordance with BS EN 771-1 [30]. The blocks were selected and their dimensions measured. They were weighed and then the density was calculated.

Water absorption by capillary testing was performed in accordance with BS EN 772-11 [31]. The blocks of each mix ratio and soil type were oven dried at a temperature of $40^{\circ} \mathrm{C}$ until a consistent mass was recorded, indicating a normal dried block. The mass of the specimens were taken and recorded. The $290 \times 140 \mathrm{~mm}$ side of the specimen was immersed to a depth of $5 \mathrm{~mm}$ in a constant head-water bath for $10 \mathrm{~min}$. The mass of the absorbed specimen was recorded and the absorption of water by capillarity rise was then calculated.

Linear shrinkage of the specimen was determined by measuring the length of the specimen with a dial gauge before and after drying.

\subsubsection{Mechanical properties test}

The compressive test was conducted in accordance with BS EN 772-1 [32]. A CONTROLS 50-C46G2 testing machine, maximum capacity $2000 \mathrm{kN}$, was used. The load was applied at a rate of $0.05 \mathrm{~N} / \mathrm{mm}^{2} / \mathrm{s}$ until the block failed, the load at which the blocks failed was recorded and maximum compressive stress was calculated.

The tensile splitting test was conducted in accordance with BS EN 12390-6 [33] with the testing machine and splitting jig which were placed centrally above and below the block. The load was applied continuously at a study rate of $0.05 \mathrm{~N} / \mathrm{mm}^{2} / \mathrm{s}$ up to failure of the block, and tensile splitting strength calculated. 


\subsubsection{Durability properties tests}

The wetting and drying (wearing) test was conducted in accordance with ASTM D559-03 [34]. Each block was immersed in water bath for $2 \mathrm{~min}$, removed and dried in an oven at a $105^{\circ} \mathrm{C}$ temperature for $24 \mathrm{hr}$. Eighteen vertical wire brush strokes of approximately $13.3 \mathrm{~N}$ force for each stroke were applied to each side of the block and four strokes to each end completing a cycle. The wearing performance of the blocks was expressed as percentage of dry mass reduction after 12 cycles relative to the original mass.

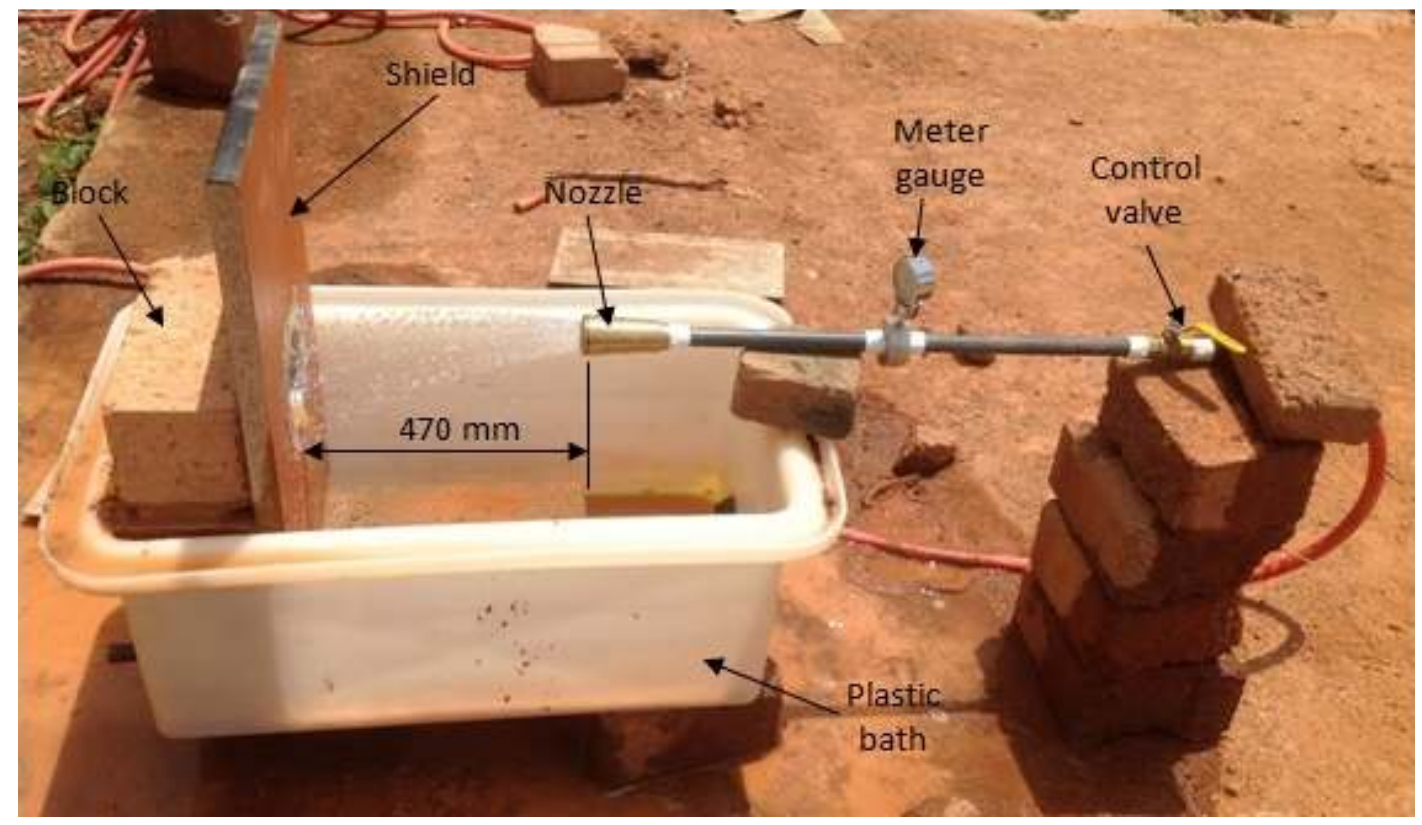

Figure 5: Water spray test set-up

The erosion test was conducted in accordance with Section D of New Zealand Standard NZS 4298 [35]. The test rig was set up (Fig 5) with a shield board positioned in a plastic bath and the pressure spray nozzle set on the bath at a distance of $470 \mathrm{~mm}$ from the shield. The rate of erosion was expressed as the pitting depth $(\mathrm{mm})$ per minute of exposure to the spray water.

\subsection{Statistical analysis}

Correlations were carried-out to establish relationships between properties measured. As each test was to a different sample, conventional pairwise comparisons were not possible; instead, the mean results were used and ranges noted. Two-way ANOVA tests (with Minitab Version 16) were used to test for significant difference and variation between the effects of soil and fibre type. 


\section{RESULTS AND DISCUSSION}

\subsection{Physical properties}

The results obtained from dry density, water absorption and linear shrinkage tests are presented in Table 3. It can be seen that the density of the reinforced soil blocks decresed with increasing fibre contents. There reduction in density was between 7 - 9\% for soil R and $6-8 \%$ for soil B. Similar trends were seen in previous studies $[14,18]$ of reinforced soil blocks/bricks with other natural fibres. The drop in density was expected as fibres have low density of $810-500 \mathrm{~kg} / \mathrm{m}^{3}$ compared to compressed soil density of about $1780 \mathrm{~kg} / \mathrm{m}^{3}$, and therefore increase fibre content displaced soil content, which is heavier, so decreased the density of the blocks. Soil R blocks had higher density than soil B blocks, which might be due to the higher OMC of the soil or the higher clay content.

Table 3: Physical property test results of reinforced soil blocks

\begin{tabular}{|c|c|c|c|c|c|c|c|c|c|c|c|c|c|}
\hline \multirow[t]{3}{*}{ Fibre } & \multirow[t]{3}{*}{ Wt.\% } & \multicolumn{4}{|c|}{ Dry density $\left(\mathrm{kg} / \mathrm{m}^{3}\right)$} & \multicolumn{4}{|c|}{ Water absorption (\%) } & \multicolumn{4}{|c|}{ Linear shrinkage (\%) } \\
\hline & & \multicolumn{2}{|c|}{ Soil R } & \multicolumn{2}{|c|}{ Soil B } & \multicolumn{2}{|c|}{ Soil R } & \multicolumn{2}{|c|}{ Soil B } & \multicolumn{2}{|c|}{ Soil R } & \multicolumn{2}{|c|}{ Soil B } \\
\hline & & $\overline{\mathrm{x}}$ & $\sigma$ & $\overline{\mathrm{x}}$ & $\sigma$ & $\overline{\mathrm{x}}$ & $\sigma$ & $\overline{\mathrm{x}}$ & $\bar{\sigma}$ & $\overline{\overline{\mathrm{x}}}$ & $\sigma$ & $\overline{\mathrm{x}}$ & $\bar{\sigma}$ \\
\hline & 0 & 1951 & 27.29 & 1909 & 22.94 & 8.1 & 0.62 & 8.5 & 0.70 & 1.05 & 0.25 & 0.90 & 0.19 \\
\hline \multirow{4}{*}{ Bagasse } & 0.25 & & 25.35 & & & 10.4 & 06 & 10.9 & 06 & 0.83 & 0.19 & 0.77 & 0.29 \\
\hline & 0 & & & & & & & & & 52 & & & 0.19 \\
\hline & 0.75 & 18 & 10.78 & 1799 & 15.27 & 14.1 & 7 & 15.4 & 0 & .56 & 9 & 19 & 0.19 \\
\hline & 1 & 1808 & 8.97 & 1790 & 8.33 & 15.7 & 0.30 & 16.5 & 0.11 & 0.49 & 0.19 & 0.42 & 0.16 \\
\hline \multirow[t]{4}{*}{ Coconut } & 0.25 & & 23.51 & & 21.71 & 9.8 & 0.64 & 10.3 & 0.4 & 83 & 0.19 & 0.77 & 0.29 \\
\hline & & & & & & 8 & & & & 99 & & & 0.16 \\
\hline & 0.75 & 1 & 11.21 & 18 & 25.80 & 13.6 & 0.81 & 14.6 & 0.43 & 0.56 & 0.19 & 0.49 & 0.19 \\
\hline & 1 & 1795 & 13.09 & 1772 & 20.99 & 14.8 & 0.05 & 15.3 & 0.27 & 0.49 & 0.19 & 0.42 & 0.16 \\
\hline $\mathrm{Oi}$ & 0.2 & 1889 & 13.38 & 1885 & 3.9 & 9.4 & 0.25 & 9.7 & 0. & 0.83 & 0.19 & 0.76 & 0.16 \\
\hline \multirow[t]{3}{*}{ palm } & & & 18. & & 7.9 & .4 & 0.4 & 11.2 & & 6 & 6 & 2 & 0.16 \\
\hline & & & 9.42 & & 6.5 & 12.3 & 0.3 & 13.9 & & 0.56 & 0.19 & 0.42 & 0.16 \\
\hline & 1 & 1823 & 10.64 & 1802 & 14.31 & 13.6 & 0.25 & 14.3 & 0.14 & 0.42 & 0.16 & 0.35 & 0.10 \\
\hline
\end{tabular}

The water absorption of the reinforced soil blocks increased with increase fibre content and appeared to level off at higher fibre content. This results is consistent with the result of the study by Ismail and Yaacob [36] which also recorded increase in water absorption of laterite bricks with increase in oil-palm empty-fruit-bunch fibre content. The increase may be attributed to the amount of water absorbed by the cellulose of the fibres, which is due to the void volume and the amount of cellulose material present in the blocks [37]. The absorbent nature of fibres creates pathway through soil blocks, thereby allowing more water to be absorbed by the blocks $[28,29]$.

The results also indicate that the linear shrinkage of the enhanced soil blocks decreased with increase fibre content. Bouhicha et al. [12] observed a similar effect which enhanced the 
properties of soil blocks with barley straw. The addition of the fibres reduces the shrinkage as the fibres oppose the deformation of the soil matrix through friction. In addition, soil B blocks recoded better shrinkage resistance than soil R blocks, which can be attributed to the lower OMC of the soil. Another contributing factor is the plasticity index, as soil B with plasticity index of 13.9 had less shrinkage. Walker [38] found that that soil with a plasticity index of $<20$ will have marginal linear shrinkage, compared to a plasticity index $>20$, so this is consistent with published findings.

\subsection{Mechanical properties}

The compressive strength of the reinforced soil blocks increased with fibre content upto between 0.25 wt.\% and 0.5 wt.\%, and then started declining as presented in Figs 6 and 7 , respectively for soil $\mathrm{R}$ and soil $\mathrm{B}$. This trend is consistent with previous studies $[12,19,36$, 39] which used other fibres in soil blocks where an optimum strength has been followed by a subsequent decline at higher fibre inclusions.

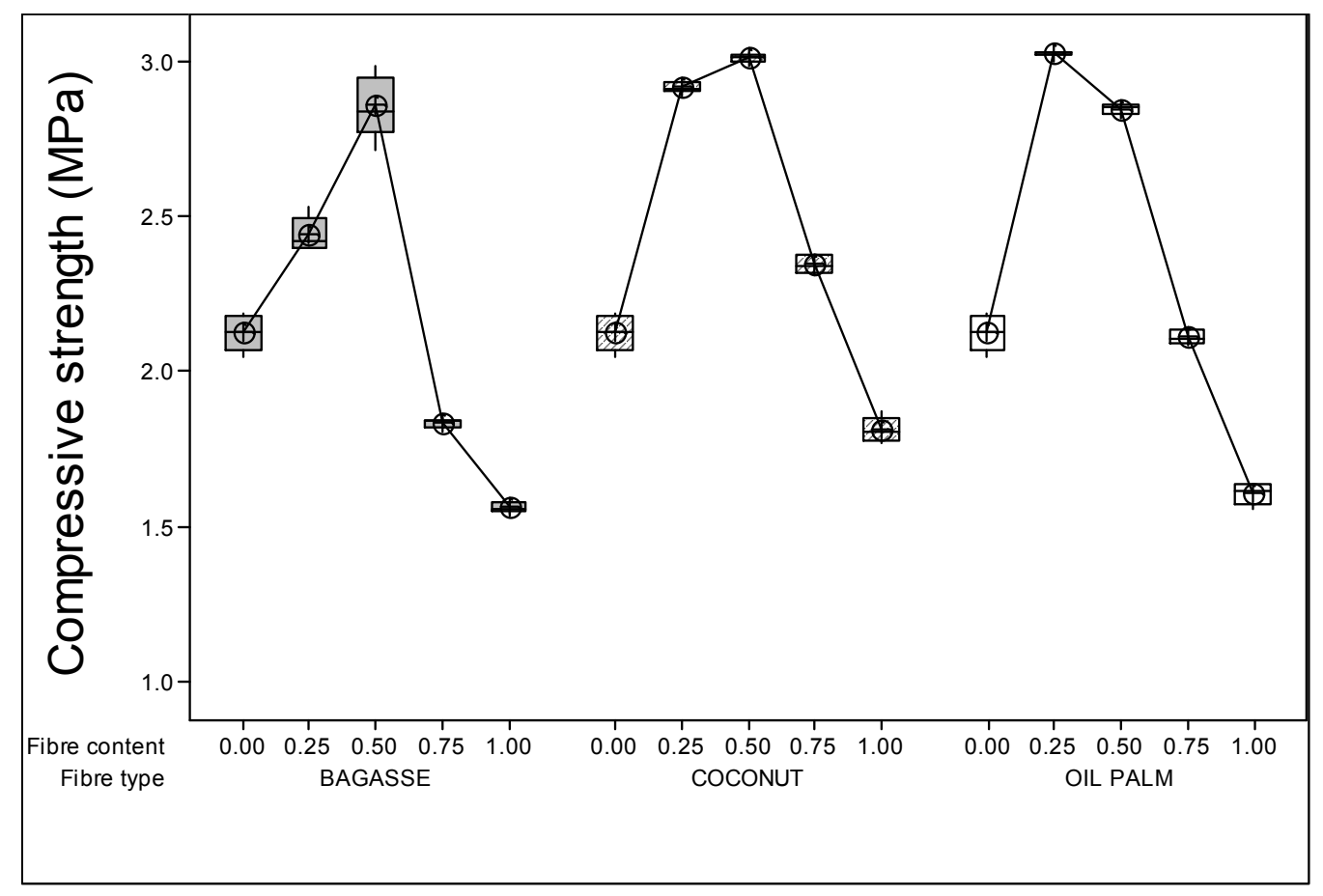

Fig. 6: Compressive strength of soil R.

Box plots represent inter-quartile range of data 


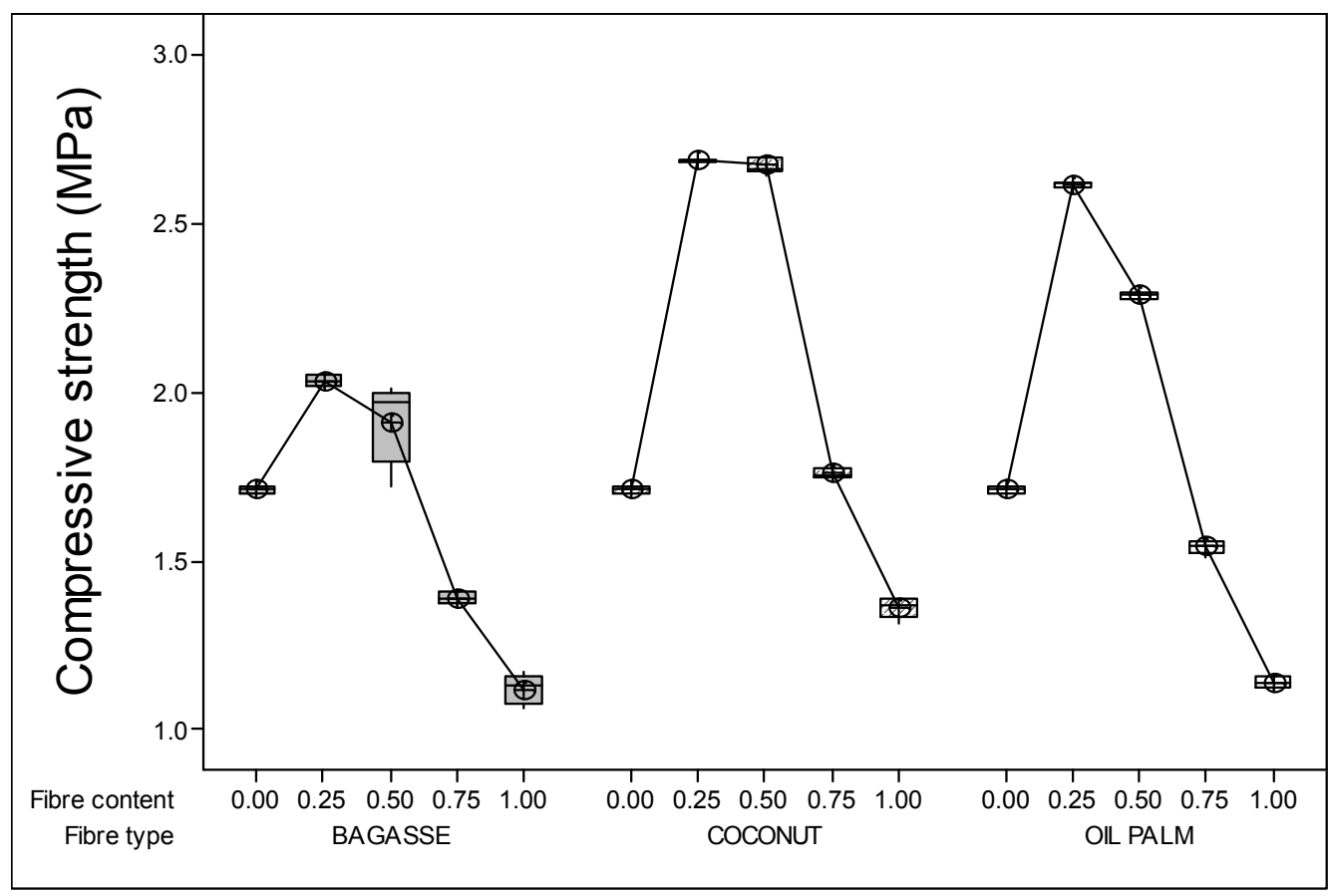

Fig. 7: Compressive strength test result of soil B.

Box plots represent inter-quartile range of data

The increase in compressive strength from unreinforced soil blocks to the optimum was $42 \%$, $41 \%$ and $21 \%$, respectively for oil palm, coconut and bagasse fibres reinforced soil blocks for soil R. While the increase for soil B was 53\%, 57\% and $18 \%$, respectively for oil palm, coconut and bagasse fibres reinforced soil blocks. Soil R obtained better optimum strength than soil B reinforced soil blocks, while soil B obtained the highest increase of reinforced over the unreinforced blocks. The increase in strength could be linked to increase friction between the fibre and the soil matrix. Furthermore, the association of fibres and the soil matrix prevents the spread of cracks in the blocks, as fibres form bridges across cracks and therefore contribute to the improved strength. Conversely, after a critical point, the increase fibre content caused strength reduction when fibres begin to knot and overlap each other [36], resulting in reduced cohesion with the soil [7] and break-up of the soil matrix [19] causing the soil-fibre composite to weaken. It is also likely that the presence of more pores due to increase fibre content in the soil matrix could lead to the reduction in strength.

Tensile strength test results are reported in Figs 8 and 9 for soil R and soil B, respectively. It can be seen that the tensile strength also displays an optimum fibre content between 0.25 wt. $\%$ and 0.5 wt.\%. The optimum points are similar for both compressive and tensile strength. 


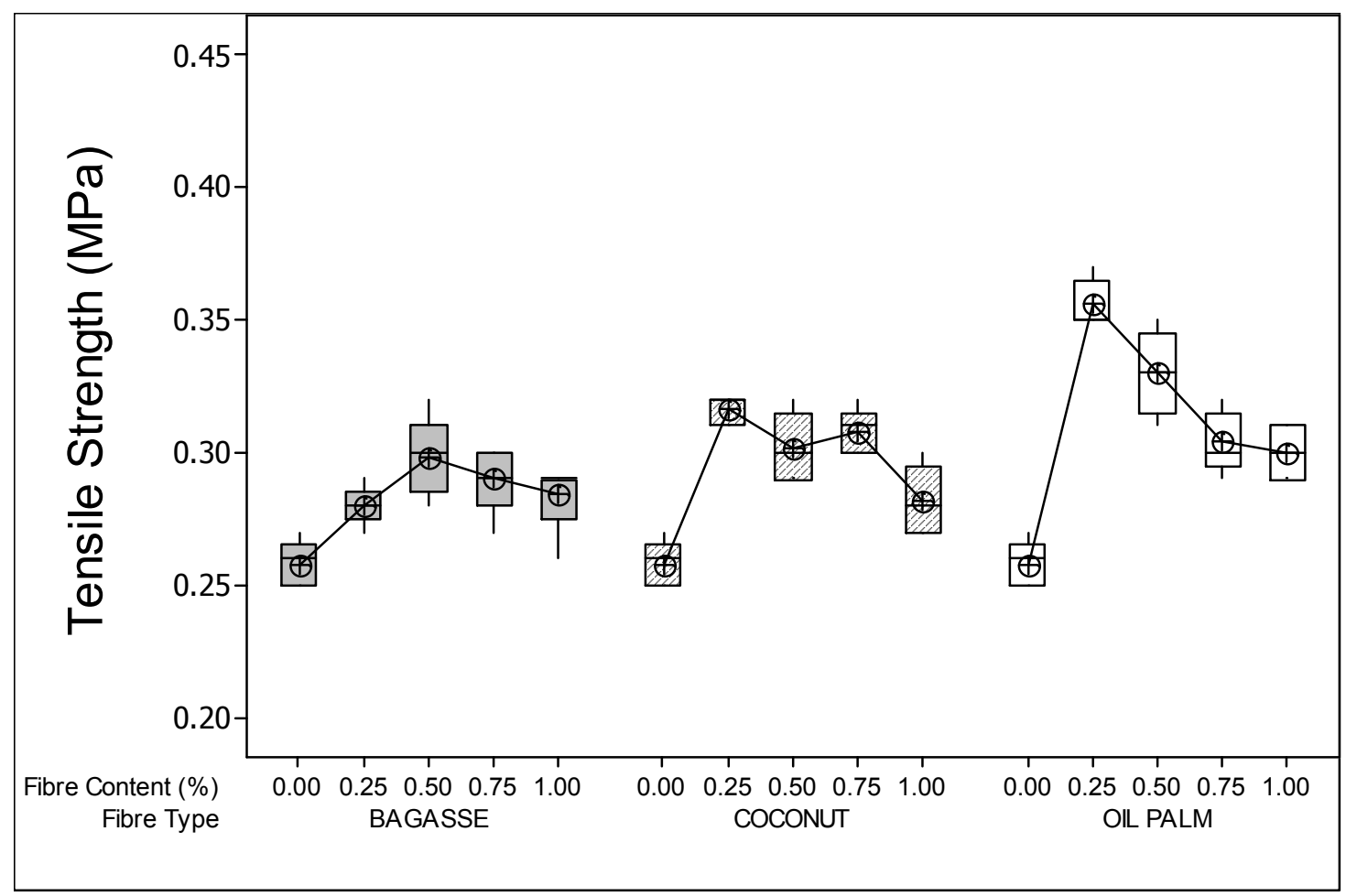

Fig. 8: Tensile strength test result of soil R.

Box plots represent inter-quartile range of data

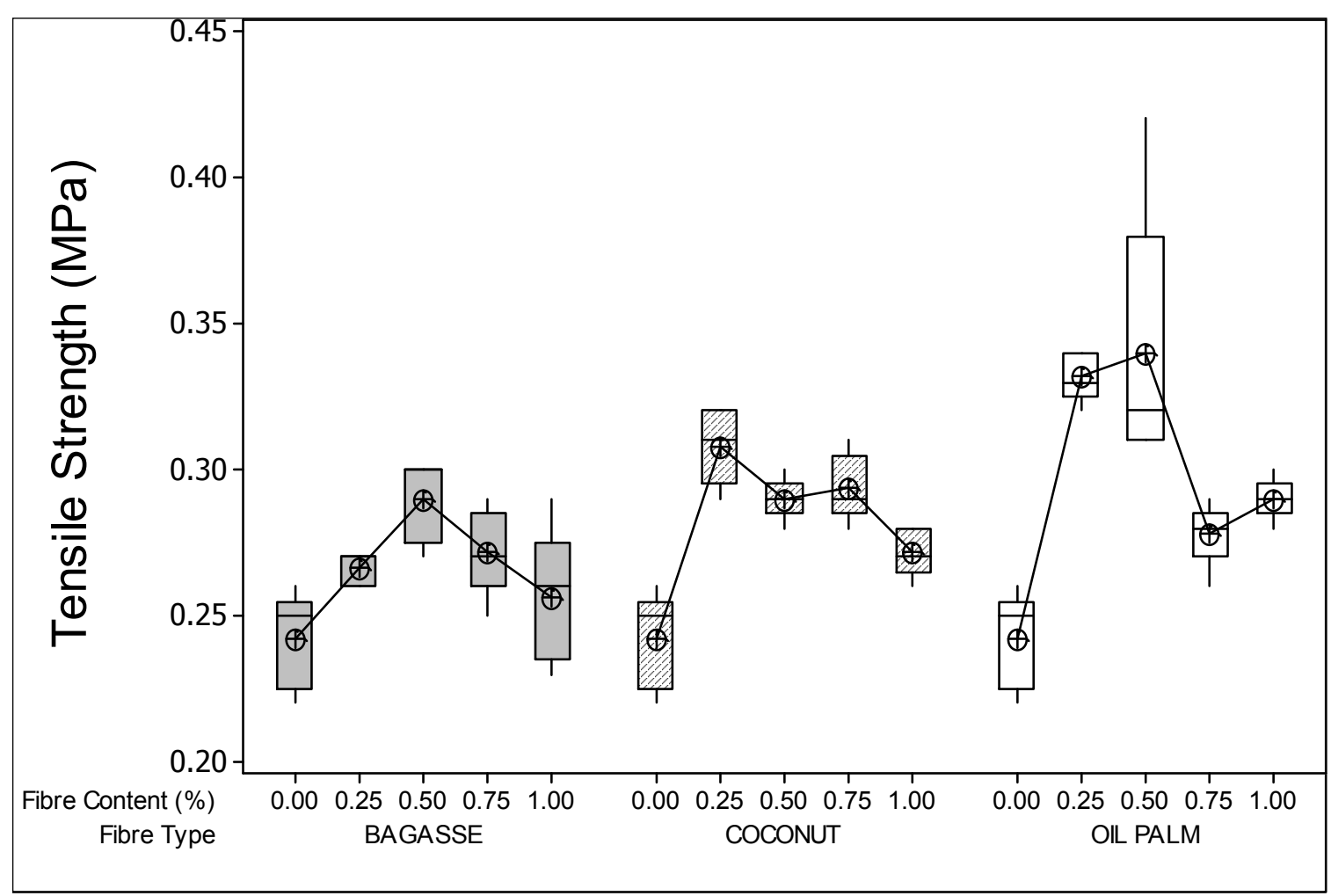

Fig. 9: Tensile strength test result of soil B.

Box plots represent inter-quartile range of data 
The reinforced soil $\mathrm{R}$ blocks had a maximum increase in mean optimal tensile strength of about $35 \%, 23 \%$ and $16 \%$, respectively for oil palm, coconut and bagasse compared to the unreinforced blocks. While soil B obtained 38\%, 29\% and $21 \%$ respective increases. It was observed that the failure of unreinforced blocks was sudden and produced only one large crack, while the failure of the fibre reinforced soil blocks was with multiple finer cracks (Fig 10). This means the failure was more gradual, acting somewhat more like a ductile material with increased fibre content, which agrees well with the findings of Bouhicha et al. [12], Cai et al. [40] and Danso et al. [2]. Upon removal of the blocks from the testing machine, though they were split into two, the two parts were still held together by the fibres. This indicates that blocks will fail slowly rather than suddenly and will still hold some load for some time after failure, though with considerable deformation.

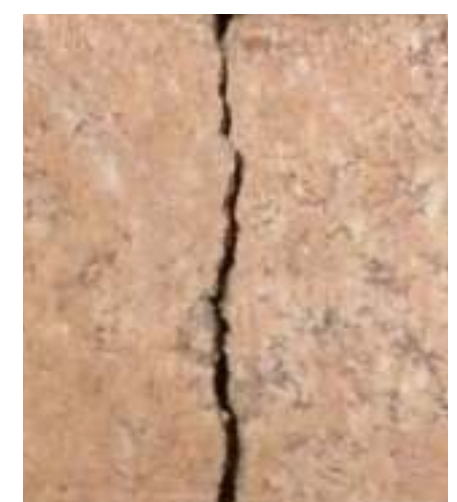

Unreinforced block

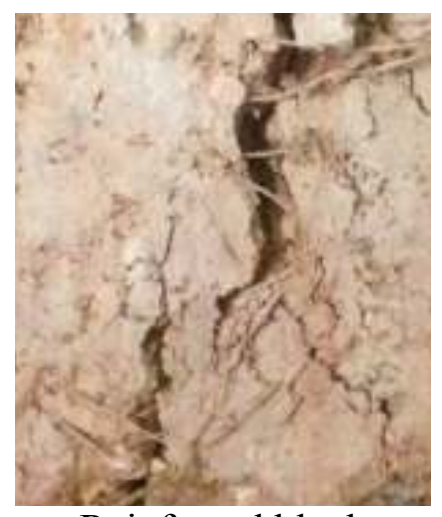

Reinforced block

Fig 10: Failure of soil blocks under tensile force

Although the pattern of compressive and tensile strengths increased together (Fig. 11), none of the correlations for each fibre and soil type were significant $(0.170>\mathrm{p}>0.686)$. Indicating that while generally a block that is strong in compression will also be strong in tension, compressive testing is a poor predictor of tensile strength. This is in contrast to other studies such as those summarised by Walker [24] which reported stronger correlations between tensile and compressive strengths. However, the linear models for the coconut and oil palm fibres explained more of the variation $(0.720>r>0.625)$ than for the bagasse $(0.315>r>0.249)$ which may be explained by the rougher texture of bagasse fibres (Fig 2) and the lower tensile strength of the fibres. The scaling factor of the correlation is also higher than many previous studies with factors of between 6.6 and 14.9 being apparent from the gradient $(\mathrm{m})$ of the linear fits. 


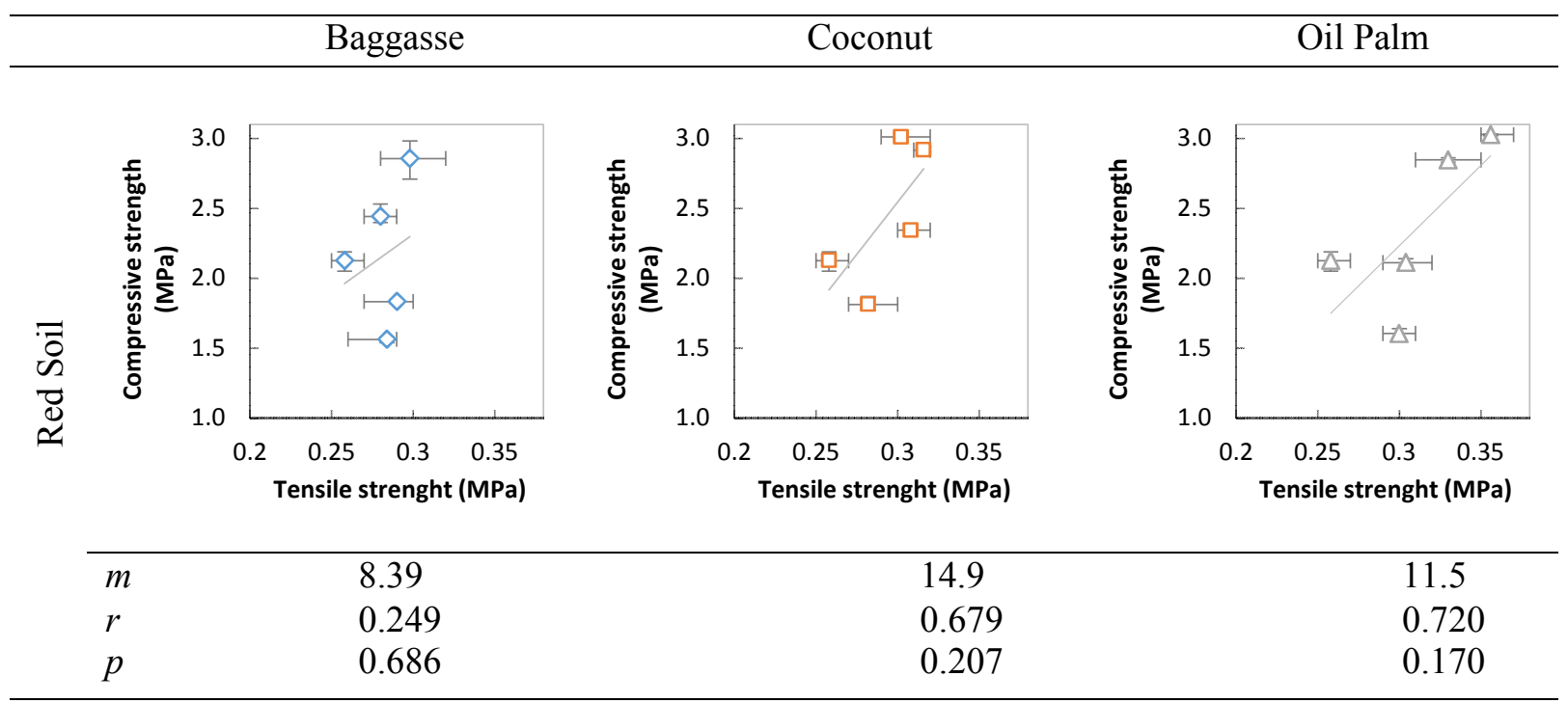
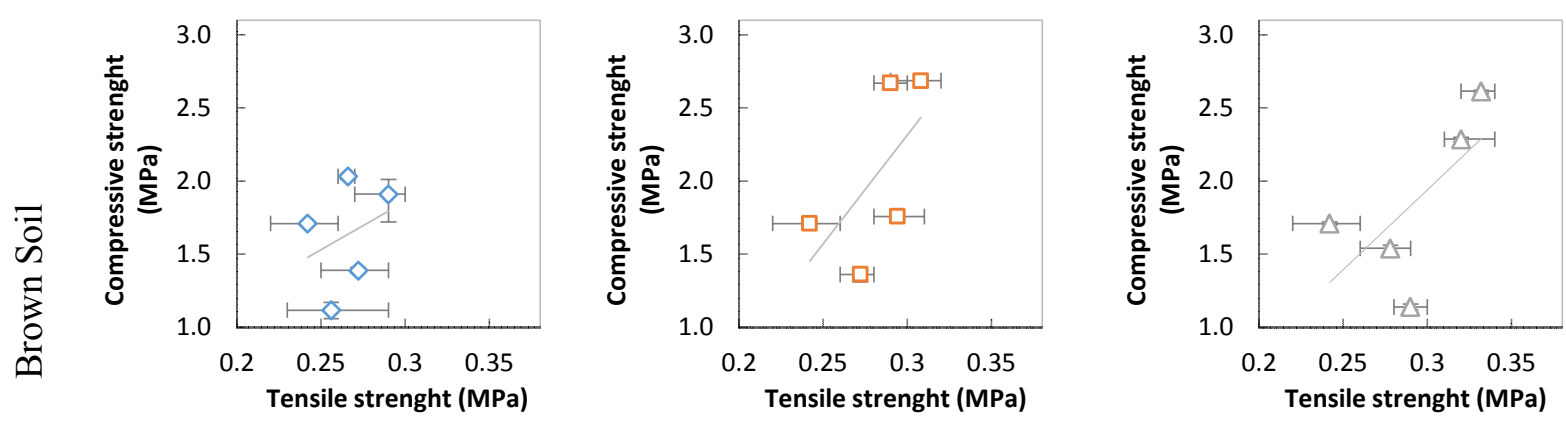

\begin{tabular}{llll}
\hline$m$ & 6.61 & 14.9 & 10.9 \\
$r$ & 0.315 & 0.625 & 0.660 \\
$p$ & 0.606 & 0.259 & 0.226 \\
\hline
\end{tabular}

Fig 11: Correlation / regression statistics for compressive vs. tensile strengths

The effectiveness of the enhancement was more pronounced with soil $\mathrm{R}$ than soil $\mathrm{B}$ in both compressive and tensile strengths, which may be primarily attributed to the higher clay content, improving bonding between fibres and the matrix. Another contributing factor is the higher $\mathrm{OMC}$ of soil $\mathrm{R}$ which aided the increased mechanical strength development of the blocks. Bagasse fibre reinforced soil blocks obtained the lowest strength, coconut and oil palm performed similarly in compression, but oil palm performed better in tension. This may be explained by the high tensile strength (Table 2) of coconut and oil palm fibres. 


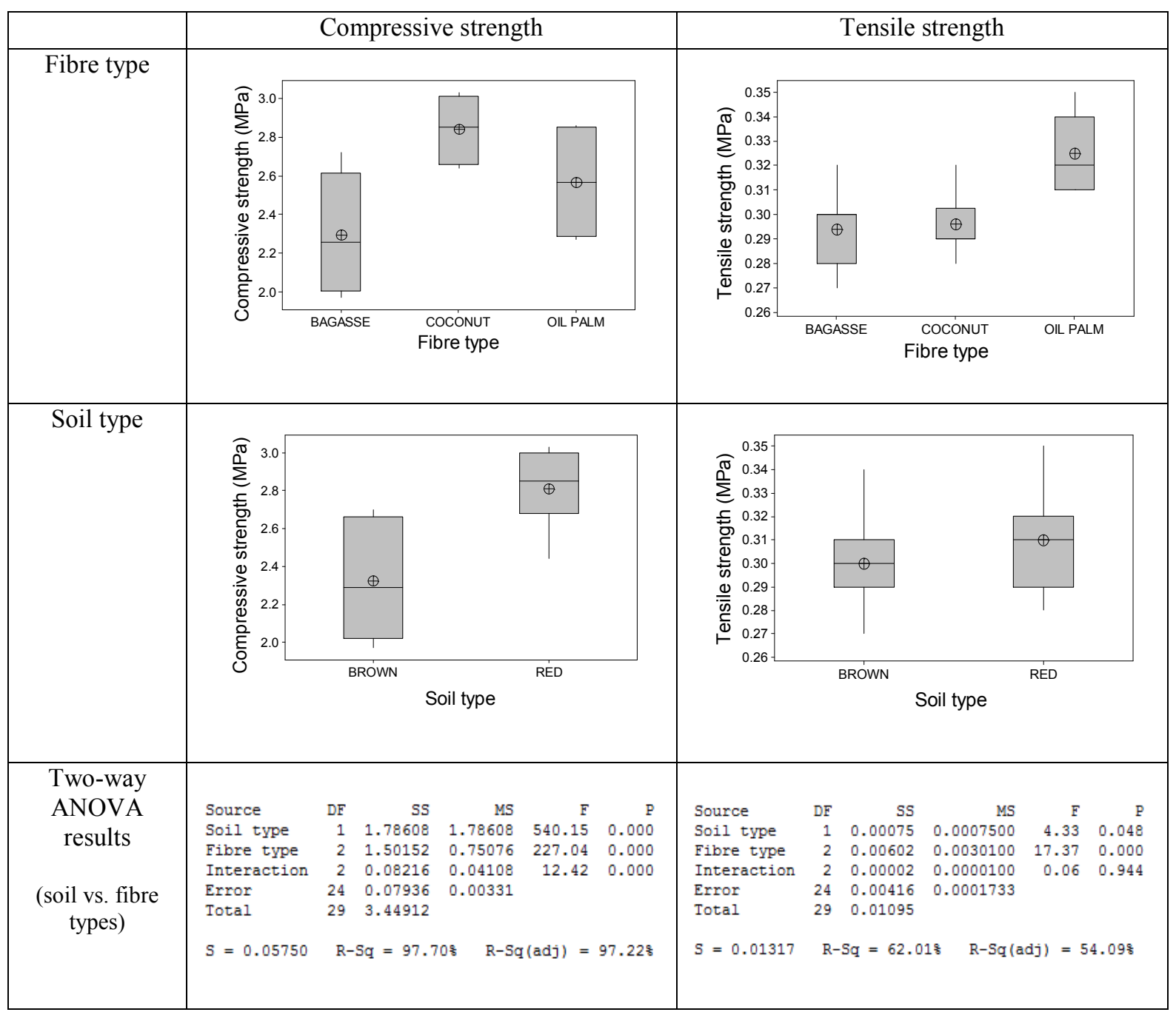

Fig 12: Two-way ANOVA statistics for fibre vs. soil types (compressive and tensile strengths). Box plots represent inter-quartile range of data

Compressive and tensile strength test results were subjected to a two-way ANOVA to determine whether fibre selection or soil selection was more important. The values used were the nominal optimum of $0.5 \mathrm{wt} . \%$ fibre content for the three fibre types and the two soil types. The results obtained are presented in Fig. 12 and show a greater variation in the compressive strength than tensile strength for both fibre and soil treatments. The ANOVA results indicate that for compressive strength, soil type $(F=540)$ is on the average dominant over fibre type $(F=227)$. On the other hand, tensile strength result suggests that the fibre 
type $(F=17)$ is dominant over soil type $(F=4)$. In both tests, statistically significant differences were found with $p<0.05$.

\subsection{Durability properties}

Results of the wearing test are presented in Figures 13 and 14, respectively for soil R and soil

B. It can be seen that there was a rapid reduction in wearing of the blocks up to $0.5 \mathrm{wt} \%$ fibre content, after which the wearing rate levels off or reverses slightly with further fibre inclusion.

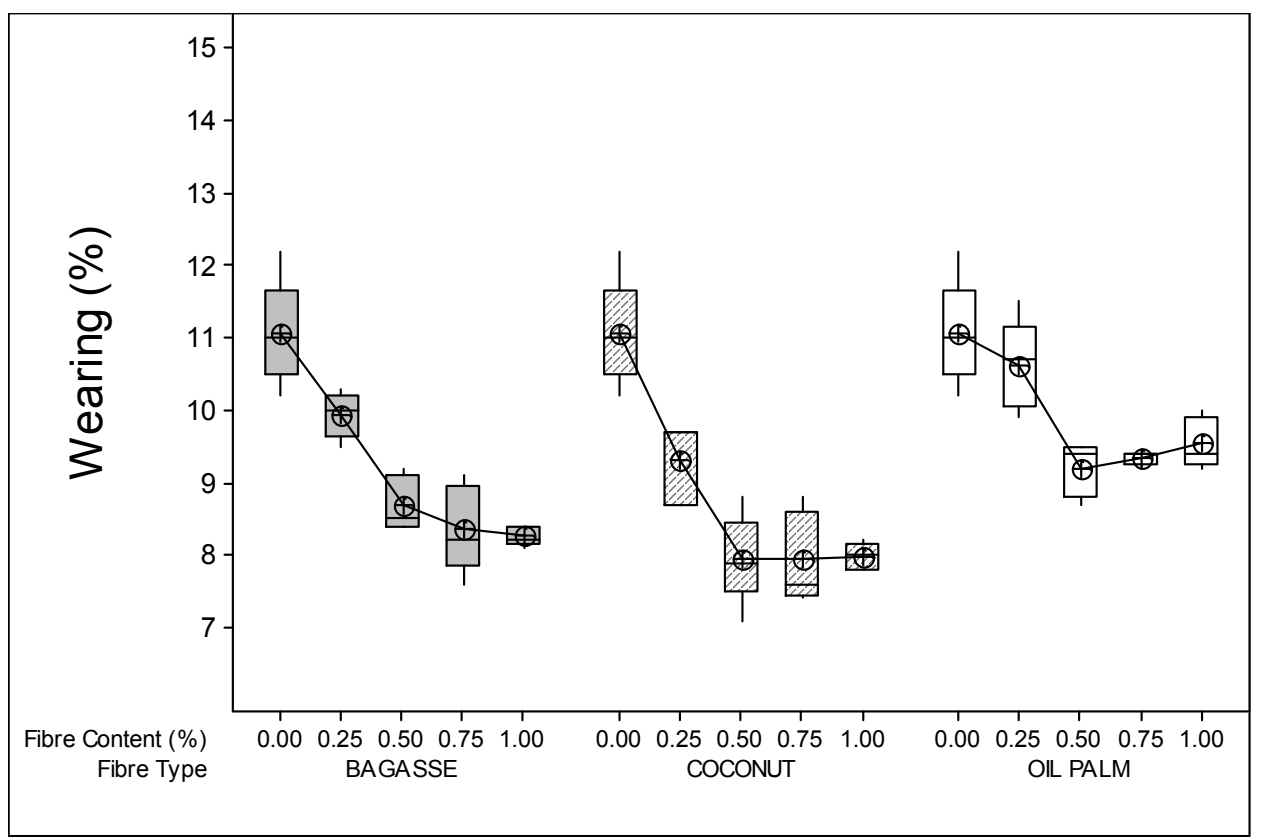

Fig. 13: Wearing test result of soil R. Box plots represent inter-quartile range of data 


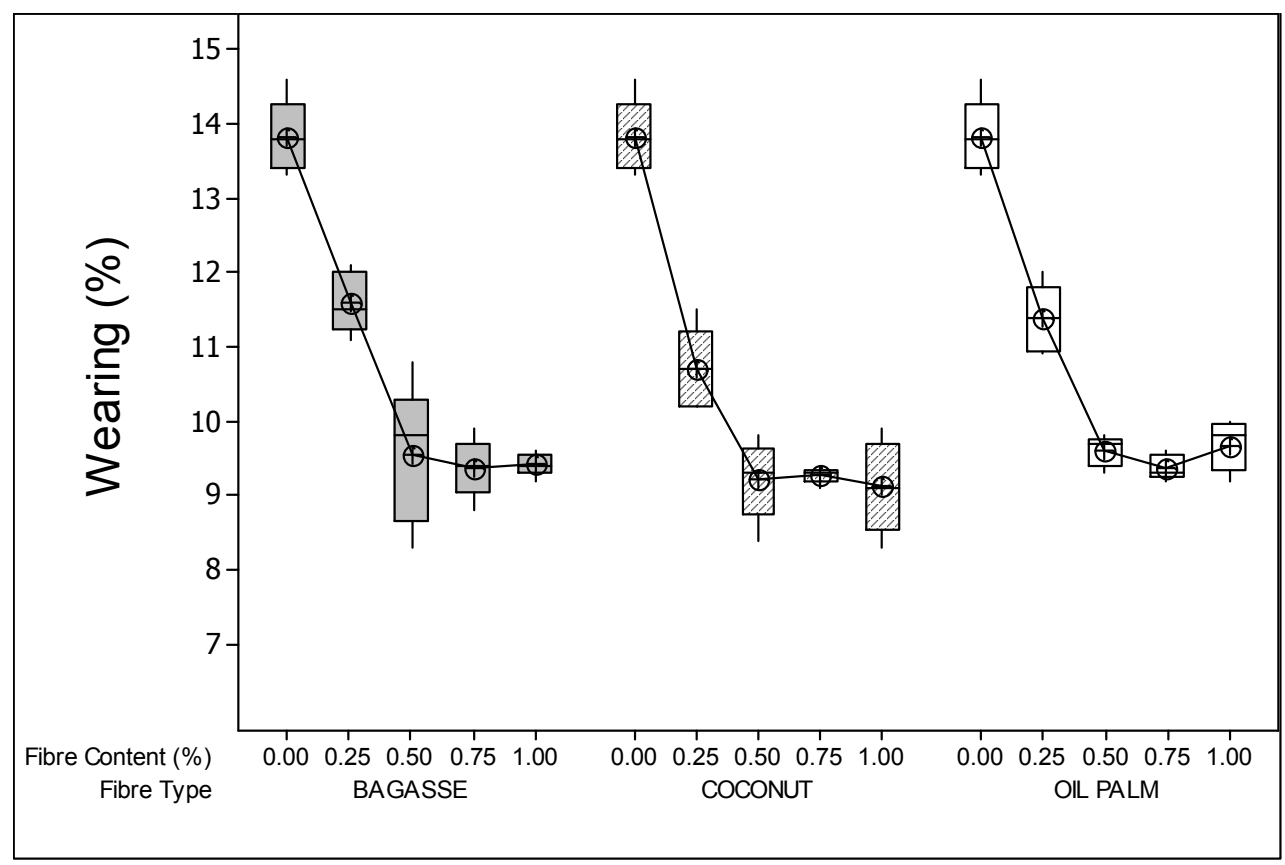

Fig. 14: Wearing test result of soil B. Box plots represent inter-quartile range of data

The greatest reduction in wearing as compared to unreinforced soil blocks was $20 \%, 38 \%$ and $33 \%$, respectively for oil palm, coconut and bagasse fibres reinforced soil blocks for soil R. While the reduction for soil B was $47 \%, 50 \%$ and $47 \%$, respectively for oil palm, coconut and bagasse fibres reinforced soil blocks. This implies that the inclusion of fibres in the soil blocks will increase the resistance of the blocks against wearing caused by external factors such as wind and human/animal activities. It should be noted that reduction in wearing after the optimum of $0.5 \mathrm{wt} . \%$ fibre content has a comparatively small effect, allowing blocks to be made with a reasonable range of fibre contents without significant deviation from optimum wearing resistance. Similarly, a study with cement as stabiliser by Yalley [41] recorded increase in abrasion (wearing) with cement increase up to 4 wt.\%, after which there was no increase with further addition of cement content.

The results presented in Figs. 15 and 16 show the same rapid reduction in erosion with increase fibre content up to $0.5 \mathrm{wt} . \%$, this then levels off and increases slightly after 0.75 wt. $\%$ fibre content for both soil types. There was between $50-70 \%$ and $44-50 \%$ reduction, respectively for soil $\mathrm{R}$ and soil $\mathrm{B}$ in the erosion for fibre reinforced soil blocks compared to the unreinforced. 


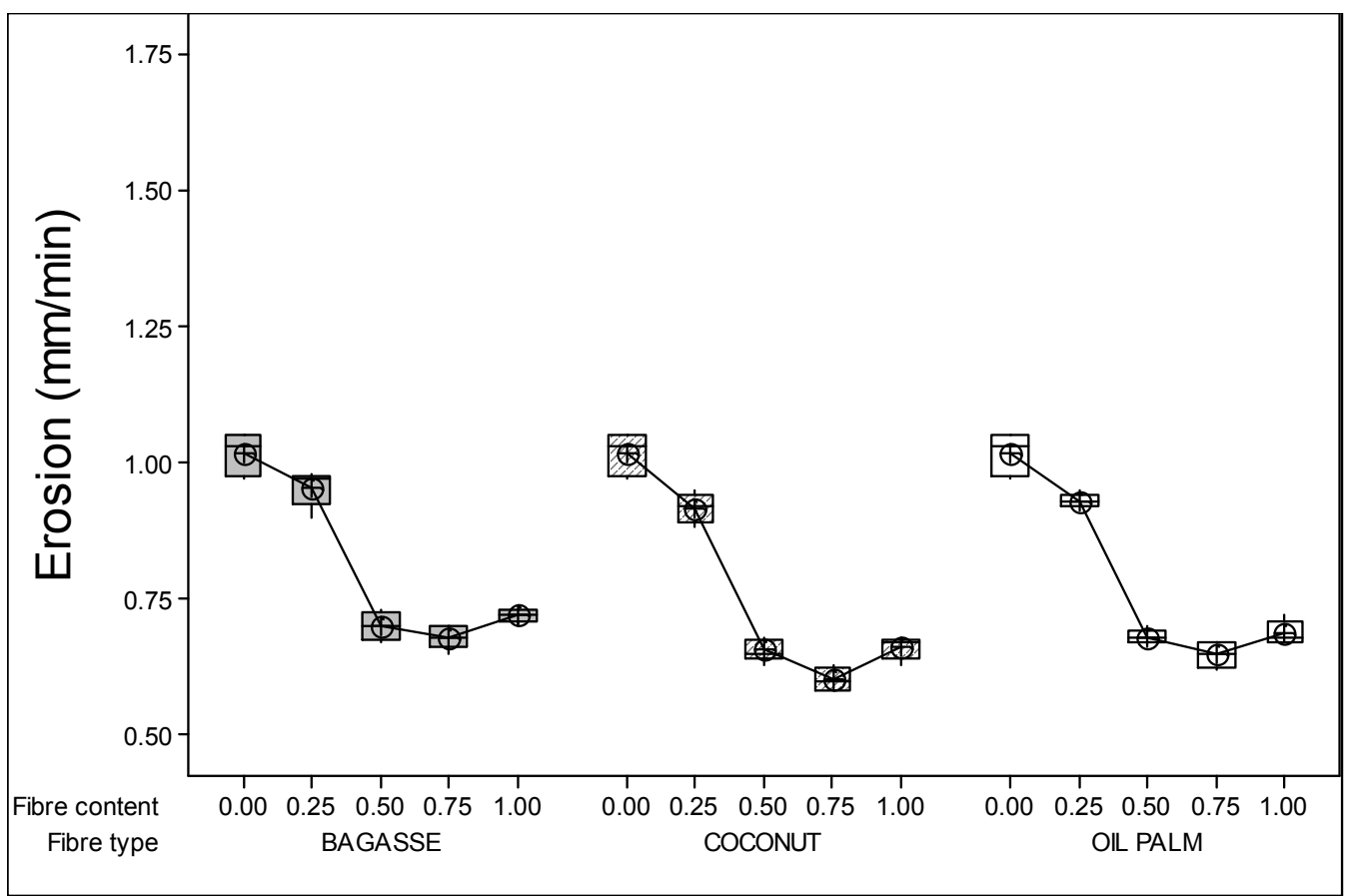

Fig. 15: Erosion test result of soil R.

Box plots represent inter-quartile range of data

The increase resistance of the reinforced soil blocks can be explained by the fibres' ability to protect the soil particles from been washed away, thereby reducing the eroding effect on the blocks. The behaviour of the fibres in the soil is similar to tree roots protecting earth from erosion [42, 43]. This test is important, particularly for high rainfall areas where erosion of earth buildings is common. There is, however a requirement to develop more climateappropriate benchmarks as proposed by Bui et al. [44]. 


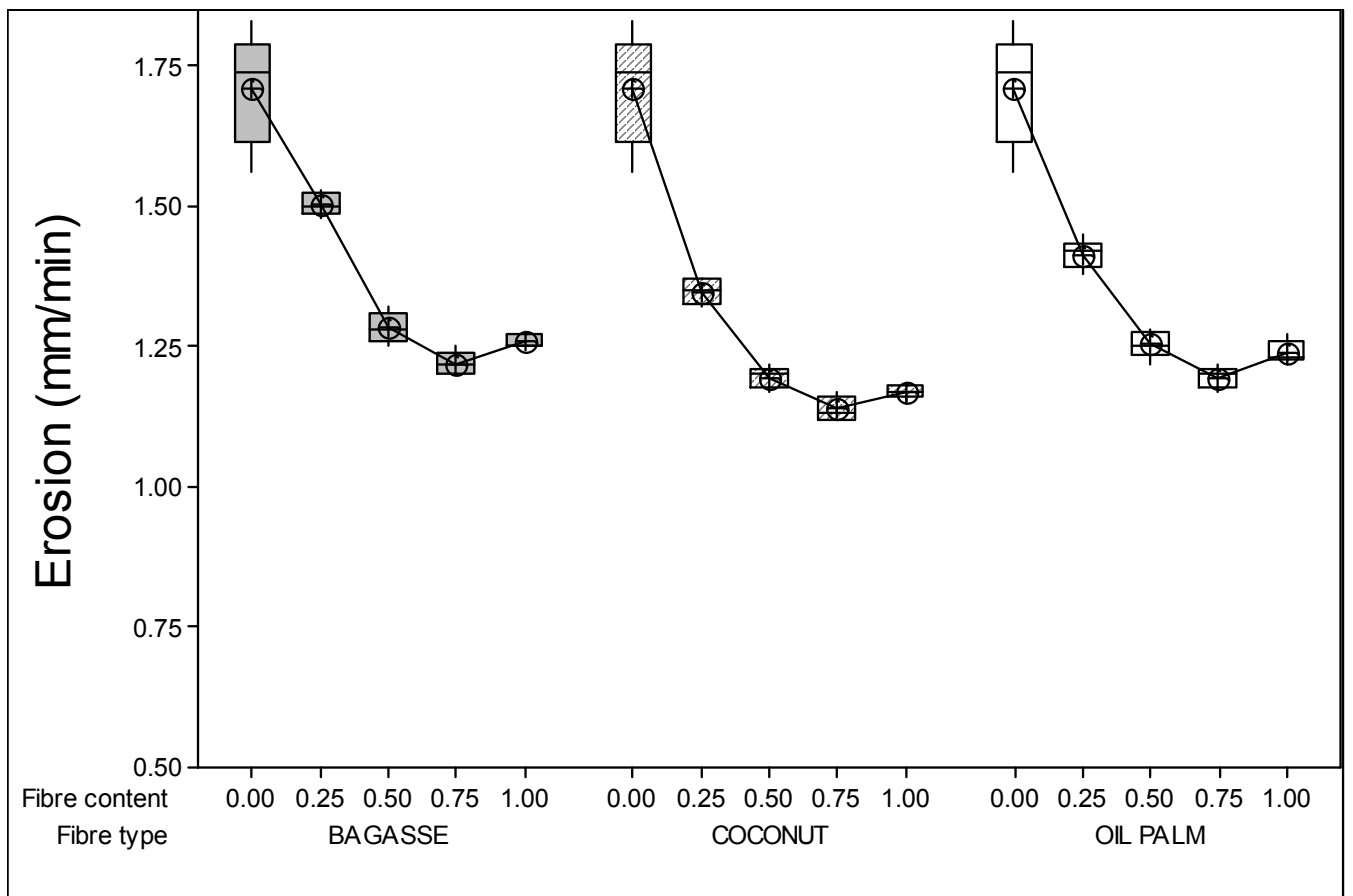

Fig. 16: Erosion test result of soil B.

Box plots represent inter-quartile range of data

The correlation/regression between wearing and erosion tests are presented in Fig 17, which display excellent correlation between the measures $(0.997>r>0.955$ and $0.00018<p<0.011)$. This suggests that it is possible to ascertain the durability of blocks with just one of these tests.

Table 4: Correlation of strength vs wearing

\begin{tabular}{|c|c|c|c|c|}
\hline \multirow{2}{*}{\multicolumn{2}{|c|}{ Tensile vs wearing }} & Baggasse & Coconut & Oil Palm \\
\hline & & & & \\
\hline \multirow{3}{*}{ 导 } & $\mathrm{m}(\mathrm{MPa} / \%)$ & -0.011 & -0.106 & -0.012 \\
\hline & $\mathrm{r}$ & -0.864 & -0.620 & -0.280 \\
\hline & $\mathrm{p}$ & 0.059 & 0.265 & 0.265 \\
\hline \multirow{3}{*}{ 竞 $=\overline{0}$} & $\mathrm{~m}(\mathrm{MPa} / \%)$ & -0.006 & -0.009 & -0.009 \\
\hline & $\mathrm{r}$ & -0.697 & -0.682 & -0.519 \\
\hline & $\mathrm{p}$ & 0.191 & 0.204 & 0.370 \\
\hline \multicolumn{5}{|c|}{ Compressive vs wearing } \\
\hline \multirow{3}{*}{$\overline{\mathscr{D}}: \overline{0}$} & $\mathrm{~m}(\mathrm{MPa} / \%)$ & 0.108 & -0.047 & 0.102 \\
\hline & $\mathrm{r}$ & 0.258 & -0.127 & -0.280 \\
\hline & $\mathrm{p}$ & 0.676 & 0.839 & 0.816 \\
\hline \multirow{3}{*}{ 竞 } & $\mathrm{m}(\mathrm{MPa} / \%)$ & 0.083 & -0.031 & 0.052 \\
\hline & $\mathrm{r}$ & 0.428 & -0.102 & 0.165 \\
\hline & $\mathrm{p}$ & 0.472 & 0.870 & 0.791 \\
\hline
\end{tabular}


A number of studies $[23,24]$ have suggested that physical properties such as mechanical strength or density may be used as proxy measures for durability for blocks stabilised using binders. To ascertain if this also holds for fibre reinforced blocks, correlation and regression tests were performed on compression and tensile strengths compared to wearing, density to wearing and water absorption to erosion. The results of the strength correlations are presented in Table 4 and the physical correlations in Table 5.

Table 5: Physical vs durability properties

\begin{tabular}{|c|c|c|c|c|}
\hline \multirow{2}{*}{\multicolumn{5}{|c|}{ Density vs. wearing }} \\
\hline & & & & \\
\hline \multirow{3}{*}{$\overline{\mathscr{Q}} \overline{\mathscr{0}}$} & $m\left(\% /\left(\mathrm{kg} / \mathrm{m}^{3}\right)\right)$ & 48.20 & 43.30 & 43.70 \\
\hline & $r$ & 0.978 & 0.971 & 0.751 \\
\hline & $p$ & 0.004 & 0.006 & 0.143 \\
\hline \multirow{3}{*}{ 旁 $\overline{0}$} & $\mathrm{~m}\left(\% /\left(\mathrm{kg} / \mathrm{m}^{3}\right)\right)$ & 26.10 & 23.50 & 18.10 \\
\hline & $\mathrm{r}$ & 0.994 & 0.936 & 0.801 \\
\hline & $\mathrm{p}$ & 0.001 & 0.019 & 0.100 \\
\hline \multicolumn{5}{|c|}{ Water absorption vs. erosion } \\
\hline \multirow{3}{*}{$\overline{\mathscr{Q}} \overline{\mathscr{\delta}}$} & $m((\mathrm{~mm} / \mathrm{min}) / \%)$ & -0.047 & -0.061 & -0.064 \\
\hline & $r$ & -0.888 & -0.916 & -0.845 \\
\hline & $p$ & 0.044 & 0.029 & 0.071 \\
\hline \multirow{3}{*}{ 旁 $=\overline{0}$} & $m((\mathrm{~mm} / \mathrm{min}) / \%)$ & -0.060 & -0.075 & -0.071 \\
\hline & $r$ & -0.943 & -0.905 & -0.857 \\
\hline & $p$ & 0.016 & 0.035 & 0.064 \\
\hline
\end{tabular}

Mechanical properties are, unfortunately very poorly correlated to wearing with both positive and negative relations, $-0.106<m<0.108$ and poor significance, $0.059<p<0.870$. The relationships of physical properties to durability are in stark contrast with recommendations for binder stabilised blocks. Lower densities and greater water absorption actually result in more durable blocks. 


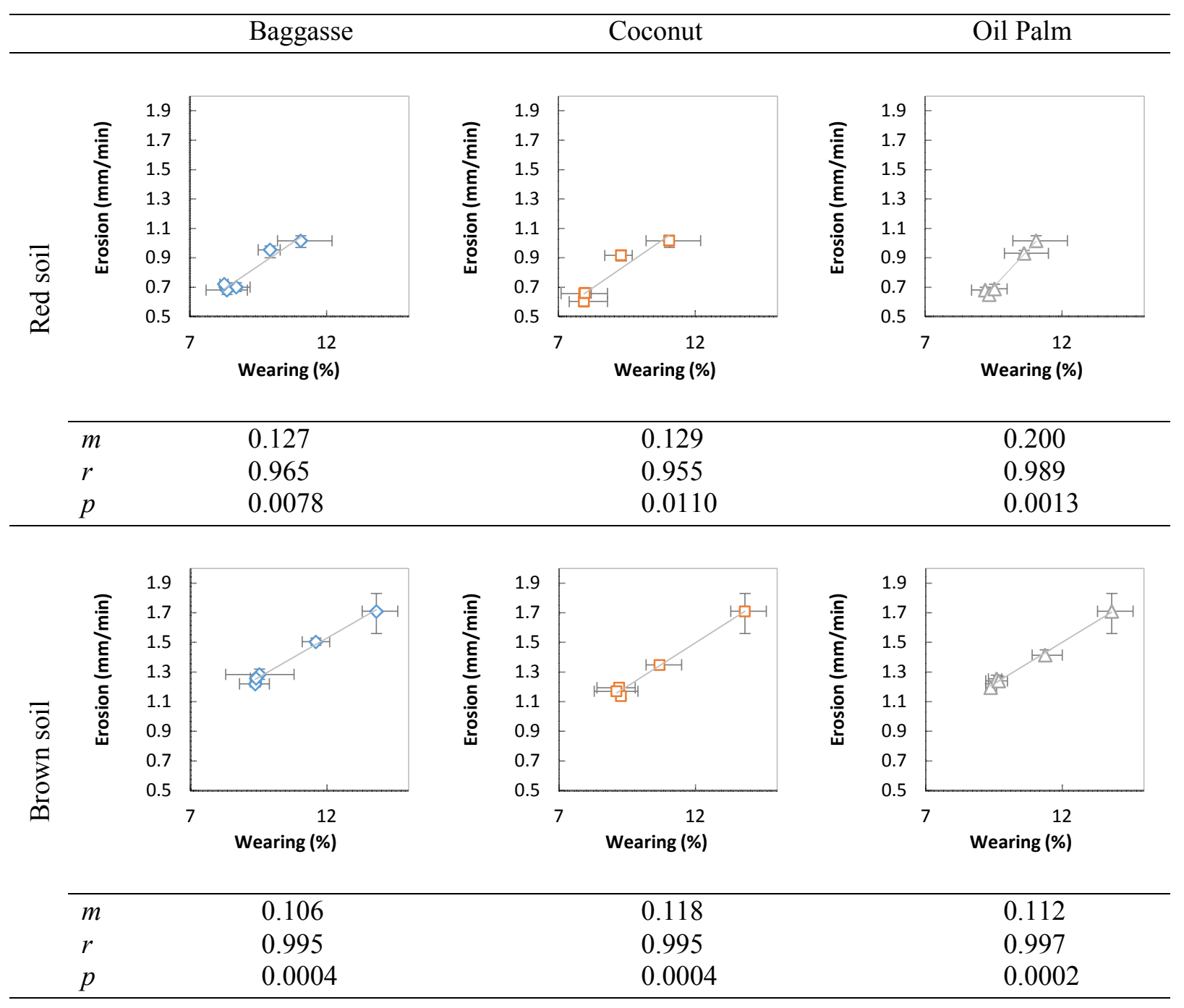

Fig 17: Correlation / regression statistics for erosion vs. wearing

As with the mechanical properties, wearing and erosion test results were subjected to a Twoway ANOVA to determine whether fibre selection or soil selection is more important for durability. The results obtained are presented in Fig 18 and show fibre type actually making very little difference $(F=2.80$ for wearing and 1.53 for erosion and with $p<0.05$ in both cases) but soil dominating, particularly for erosion $(F=358, p<0.005)$. The effectiveness of the enhancement was more pronounced with soil R (high clayey soil) than soil B (low clayey soil) in both wearing and erosion. 


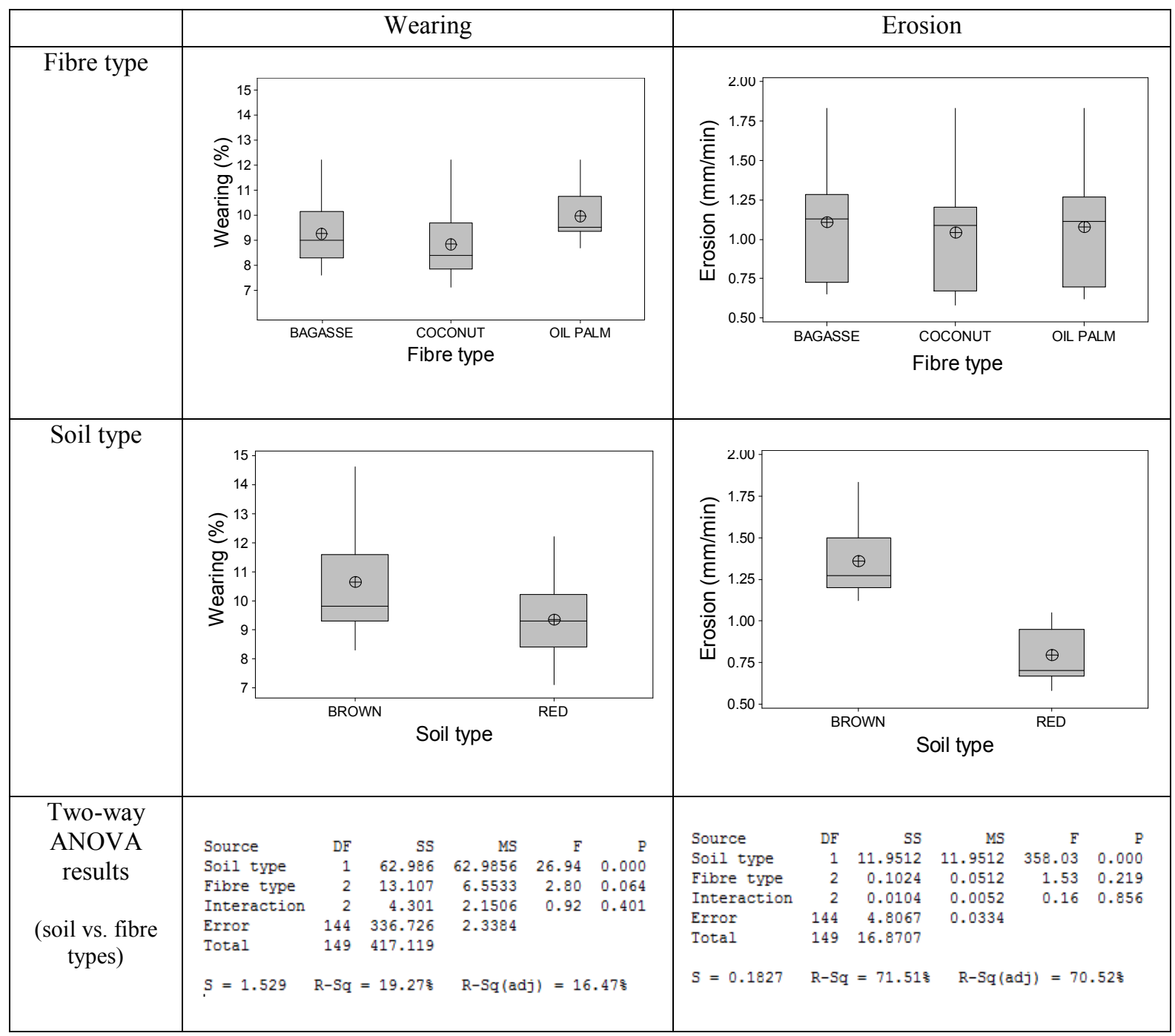

Fig 18: Two-way ANOVA statistics for fibre vs. soil types (wearing and erosion). Box plots represent inter-quartile range of data

\section{CONCLUSION}

This study presents the properties of soil building blocks enhanced with coconut husk fibres, oil palm nut fruit fibres and sugarcane bagasse fibres for a soil that would normally be selected for block making and also for a soil with a higher clay content than recommended. On the basis of the test results obtained from the experiments, the following conclusions can be drawn:

- The addition of the agricultural waste fibres to the soil blocks contributed to a reduction in density and linear shrinkage of the blocks, but increased water absorption. This means that the blocks will contribute to a reduction in weight of structures and have reduced cracking. They will, however allow greater water ingress 
which may be problematic for damp inside the building, however the ingress does not correlate with increased erosion as would normally be assumed.

- Compressive strength and tensile strength of the reinforced soil blocks is greater than unreinforced soil blocks, and the optimum effectiveness of the enhancement was obtained between $0.25 \mathrm{wt} \%$ and $0.5 \mathrm{wt} . \%$ content of the fibres to the soil. The agricultural waste fibres inclusion in soil blocks improved the mechanical properties of the blocks with an increase in strength of between $16 \%$ and $57 \%$. Coconut and oil palm fibre reinforced blocks were more effective than bagasse reinforced soil blocks.

- The use of the agricultural waste fibres as reinforcement in the soil blocks reduced the rate of wearing by $20 \%$ to $50 \%$ and erosion of the soil blocks by $44 \%$ to $70 \%$ when subjected to wetting and drying, and water spray tests. The effect of fibre was, however smaller than soil selection. Soil with a high clay content, even with no fibres, outperformed a soil more in-keeping with current recommendations for soil blocks.

- There was a clear strength optimum of $0.25 \mathrm{wt} . \%$ to $0.5 \mathrm{wt} . \%$ waste fibre content but the optimum was less critical for durability, which was relatively stable at higher fibre content. 0.5 wt. $\%$ fibre content by weight is therefore recommended to practitioners for use in enhancing the strength and durability properties of soil blocks with the selected agricultural waste fibres.

- Extrapolation of mechanical and durability properties from physical properties is not possible. Unlike binder stabilised blocks, density is inversely correlated with strength and durability. Compressive and tensile strength are positively, but poorly correlated and both unreliably correlated with durability. Water absorption is negatively correlated with erosion.

- Soil type was found to be most important element in compressive strength development, with highly clayey soil performing better in most of the tests. While fibre type was the most important element in tensile strength development. Soil was the most important factor in durability with clayey soil performing best, contrary to normal recommendations [25] which are based on the needs of binder stabilised blocks.

- The reinforced soil blocks are suitable for use as a building material which is very important for less economically developed countries, particularly Ghana, because of abundance and low-cost of coconut husk, sugarcane bagasse and oil palm fruit fibres. 


\section{References}

[1] Safiuddin M, Jumaat MZ, Salam MA, Islam MS, Hashim R. Utilization of solid wastes in construction materials. Int. J. Phys Sci 2010;5(13):1952-63.

[2] Danso H, Martinson DB, Ali M, Williams J. Effect of fibre aspect ratio on mechanical properties of soil building blocks. Constr Build Mater 2015;83:314-9, doi:10.1016/j.conbuildmat.2015.03.039.

[3] Kriker A, Bali A, Debicki G, Bouziane M, Chabannet M. Durability of date palm fibres and their use as reinforcement in hot dry climates. Cem Conc Compos 2008;30:639-48. doi:10.1016/j.cemconcomp.2007.11.006.

[4] Li Y, Sun Y. Preliminary study on combined-alkali-slag paste materials. Cem Conc Res 2000;30:963-6.

[5] Degirmenci N. The using of waste phosphogypsum and natural gypsum in adobe stabilization. Constr Build Mater 2008;22:1220-4, doi:10.016/j.conbuildmat.2007.01.027.

[6] Villamizar MCN, Araque VS, Reyes CAR, Silva RS. Effect of the addition of coal-ash and cassava peels on the engineering properties of compressed earth blocks. Constr Build Mater 2012;36:276-86, doi.org/10.1016/j.conbuildmat.2012.04.056.

[7] Medjo Eko R, Offa ED, Ngatcha TY, Minsili LS. Potential of salvaged steel fibers for reinforcement of unfired earth blocks. Constr Build Mater 2012;35:340-6, doi.org/10.1016/j.conbuildmat.2011.11.050.

[8] Vilane BRT. Assessment of stabilisation of adobes by confined compression tests. Biosystems Eng 2010;106:551-8, doi:10.1016/j.biosystemseng.2010.06.008.

[9] Turgut P, Yesilata B. Physico-mechanical and thermal performances of newly developed rubber-added bricks. Energy Build 2008;40(5):679-88, doi:10.1016/j.enbuild.2007.05.002.

[10] Subramaniaprasad CK, Abraham BM, Nambiar EKK. Sorption characteristics of stabilised soil blocks embedded with waste plastic fibres. Constr Build Mater 2014;63:25-32, http://dx.doi.org/10.1016/j.conbuildmat.2014.03.042.

[11] Aymerich F, Fenu L, Meloni P. Effect of reinforcing wool fibres on fracture and energy absorption properties of an earthen material. Constr Build Mater 2012;27:66-72, doi:10.1016/j.conbuildmat.2011.08.008.

[12] Bouhicha M, Aouissi F, Kenai S. Performance of composite soil reinforced with barley straw. Cem Concr Compos 2005;27:617-21, doi:10.1016/j.cemconcomp.2004.09.013.

[13] Parisi F, Asprone D, Fenu L, Prota A. Experimental characterization of Italian composite adobe bricks reinforced with straw fibers. Compos Struct 2015;122:300-7, http://dx.doi.org/10.1016/j.compstruct.2014.11.060.

[14] Demir I. An investigation on the production of construction brick with processed waste tea. Build Environ 2006;49(1):1274-8, doi:10.016/j.buildenv.2005.05.004. 
[15] Achenza M, Fenu L. On earth stabilization with natural polymers for earth masonry construction. Mater Struct 2006;39:21-7, DOI 10.1617/s11527-005-9000-0.

[16] Kolop R, Haziman WIM, Eng JW. Properties of cement blocks containing high content of oil palm empty fruit bunches (EFB) fibers. International Conference on Civil Engineering Practice (ICCE08). Kuantan, Pahang, Malaysia: Universiti Tun Hussein Onn Malaysia; 2010.

[17] Juárez C, Guevara B, Valdez P, Durán-Herrera A. Mechanical properties of natural fibers reinforced sustainable masonry. Constr Build Mater 2010;24:1536-41.

[18] Chan CM. Effect of natural fibers inclusion in clay bricks: physico-mechanical properties. Int J Civil Environ Eng 2011;3(1):51-7.

[19] Millogo Y, Morel J-C, Aubert J-E, Ghavami K. Experimental analysis of pressed adobe blocks reinforced with hibiscus cannabinus fibers. Constr Build Mater 2014;52:71-8.

[20] Taallah B, Guettala A, Guettala S, Kriker A. Mechanical properties and hygroscopicity behavior of compressed earth block filled by date palm fibers. Constr Build Mater 2014;59:161-8, http://dx.doi.org/10.1016/j.conbuildmat.2014.02.058.

[21] Aguwa JI. Study of coir reinforced laterite blocks for buildings. J Civil Eng Constr Technol 2013;4(4):110-5, DOI 10.5897/JCECT2013.0253.

[22] Sreekumar MG, Nair DG. Stabilized lateritic blocks reinforced with fibrous coir wastes. Int J Sustainable Constr Eng Technol 2013;4(2):23-32.

[23] Venkatarama Reddy BV, Jagadish KS. Influence of soil composition on strength and durability of soil-cement blocks. The Indian Concr J. 1995;69(9):517-24.

[24] Walker PJ. Strength and erosion characteristics of earth blocks and earth block masonry. J Mater Civil Eng 2004;16(5):497-506, DOI: 10.1061/(ASCE)0899-1561(2004)16:5(497).

[25] Houben H, Guillaud H. Earth construction: a comprehensive guide. London: International Technology Publications; 1994.

[26] USCS. The Unified Soil Classification System (USCS). http://infohost.nmt.edu/ Mehrdad/ME420/assets/pdf/USCS.pdf. 1952.

[27] BS EN ISO 17294-1. Water quality. Application of inductively coupled plasma mass spectrometry (ICP-MS). General guidelines.

http://shop.bsigroup.com/ProductDetail/?pid=000000000030160656. 2006.

[28] Ghavami K, Filho RDT, Barbosac NP. Behaviour of composite soil reinforced with natural fibres. Cem Concr Compos 1999;21:39-48.

[29] Danso H, Martinson B, Ali M, Mant C. Performance characteristics of enhanced soil blocks: a quantitative review. Build Res Inform 2015;43(2):253-62. DOI: 10.1080/09613218.2014.933293.

[30] BS EN 771-1. Specification for masonry units. Clay masonry units. European Standard adopted by British Standards Institution:

http://shop.bsigroup.com/ProductDetail/?pid=000000000030142472. 2003. 
[31] BS EN 772-11. Methods of test for masonry units. European Standardn adopted by British Standards Institution:

http://shop.bsigroup.com/ProductDetail/?pid=000000000030215381. 2011.

[32] BS EN 772-1. Methods of test for masonry units. Determination of compressive strength. European Standardn adopted by British Standards Institution:

http://shop.bsigroup.com/ProductDetail/?pid=000000000030215378 2011 .

[33] BS EN 12390-6. Testing hardened concrete. Tensile splitting strength of test specimens. European Standard adopted by British Standards Institution: https://www.documentcenter.com/standards/show/BS-EN-12390-6. 2009.

[34] ASTM D559-03. Standard test methods for wetting and drying compacted soil-cement mixtures. ASTM International, West Conshohocken, PA.

http://www.astm.org/Standards/D559.htm. 2003.

[35] New Zealand Standard NZS 4298. Materials and workmanship for earth building. Standard New Zealand. http://shop.standards.co.nz/catalog/4298\%3A1998(NZS)/view. 1998.

[36] Ismail S, Yaacob Z. Properties of laterite brick reinforced with oil palm empty fruit bunch fibres. Pertanika J. Sci Technol 2011;19(1):33-43.

[37] Jeefferie AR, Nurul Fariha, O., Mohd Warikh, A. R., Yuhazri, M. Y., Sihombing, H. and Ramli, J. . Preliminary study on the physical and mechanical properties of tapioca starch / sugarcane fiber cellulose composite. J Eng Appl Sci 2011;6(4):1819-6608.

[38] Walker PJ. Strength, Durability and Shrinkage Characteristics of Cement Stabilised Soil Blocks. Cem Concr Compos 1995;17:301-10.

[39] Akbulut S, Arasan S, Kalkan E. Modification of clayey soils using scrap tire rubber and synthetic fibers. Appl Clay Sci2007;38:23-32, doi:10.1016/j.clay.2007.02.001.

[40] Cai Y, Shi B, Ng CWW, Tang C. Effect of polypropylene fibre and lime admixture on engineering properties of clayey soil. Eng Geol 2006;87:230-40,

doi:10.1016/j.enggeo.2006.07.007.

[41] Yalley PP. use of waste and low energy materials in construction. Germany: LAP LAMBERT Academic Publishing; 2012.

[42] Huat BBK, Kazemian S. Study of root theories in green tropical slope stability. The Electronic Journal of Geot Eng 2010;15:1825-34.

http://www.ejge.com/2010/Ppr10.133/Ppr10.133ar.pdf.

[43] Michalowski RL, Zhao A. Failure of fiber-reinforced granular soil. J Geot Eng 1996;121(2):152-62, http://dx.doi.org/10.1061/(ASCE)0733-9410(1996)122:3(226).

[44] Bui QB, Morel JC, Venkatarama Reddy BV, Ghayad W. Durability of rammed earth walls exposed for 20 years to natural weathering. Build Environ 2009;44:912-9, doi:10.1016/j.buildenv.2008.07.001. 